\title{
Public Interest or Regulatory Capture: Theory and Evidence from China's Airfare Deregulation
}

\author{
Kai Li, Cheryl Long, Wei Wan*
}

January 12, 2019

\begin{abstract}
The study is motivated by two seemingly contradictory patterns observed in China's airline industry with prevalent airfare caps. On the one hand, airfares tend to be higher and thus airfare caps are more likely to be binding in routes operated by fewer airlines; but on the other hand, it is in these same routes where airfare caps are more likely to be deregulated. To explain this apparent paradox, we build a simple theoretical model, which derives distinctive predictions from the public interest theory versus the capture theory of regulation. When empirically testing the model, we find more support for the public interest theory. In particular, Chinese regulators seem to genuinely care about public interests when making deregulation decisions, and their concern with market exit and the consequent failure to serve certain markets is the main reason for removing airfare caps in routes served by fewer airlines. In contrast to most studies that investigate consequences of deregulation in the airline industry, we explore the motivation for deregulation. We also contribute to the literature by emphasizing the role of universal service obligations in understanding regulatory reforms in developing countries.
\end{abstract}

Keywords: Regulatory Capture; Public Interest; Airfare Cap; Airline Deregulation

JEL Classification: D7; L5; L9

* Kai Li: Department of International Economics and Trade, School of Economics and WISE, Xiamen University. Email: likai501@gmail.com, Cheryl Long: Department of Economics, School of Economics and WISE, Xiamen University. Email: cxlong@xmu.edu.cn; Wei Wan: School of Economics and Business Administration, Central China Normal University. Email: wv200503@163.com We acknowledge financial support from the National Natural Science Foundation of China (Grant No. 71273217, Grant No. 71741001, Grant No. 71790601, and Grant No. 71790600), the National Social Science Foundation of China (Grant No. 2015MZD006), as well as the Central Higher Education Fundamental Research Fund (Grant No. 20720151001 and Grant No. 20720171067). We are grateful to Jimmy Chan for the generous sharing of the airfare data. We have also benefited from suggestions and comments at the 2018 International Conference on Industrial Economics in Zhejiang University. All errors are ours. 


\section{Introduction}

The topic of regulation has drawn attention from economists since the time of Adam Smith, with largely negative evaluations of its consequences (Rovizzi and Thompson, 1992; Djankov et al., 2002; Resende and Facanha, 2005; Danzon et al., 2005). In contrast, the study of deregulation has a shorter history. Yet in line with the critical view of regulation, research on deregulation has mostly produced evidence in support of positive economic impact (Traub and Jayne, 2008; Kang and Zarnikau, 2009; Davey, 2010; Flores and Shepherd, 2014). Against this background, we observe the following two seemingly contradictory patterns when investigating airline routes experiencing airfare cap deregulation in China: On the one hand, airfare caps are more likely to be removed in routes operated by a smaller number of airlines; On the other hand, airfares tend to be higher in routes with fewer airlines, where airfare caps are more likely to be binding.

Airlines prefer the elimination of airfare caps, which will allow them to charge higher prices, leading to potential consumer welfare loss. Thus, the removal of price caps in routes where the caps are more likely to be binding suggests the deregulation process may have imposed a detrimental effect on consumer welfare, instead of the beneficial effect predicted by the literature on deregulation. The two patterns summarized above therefore motivate us to answer the following question: Why are airfare caps more likely to be removed in routes with fewer airlines, although airfares tend to be higher and thus the caps more likely to be in effect in these routes? Alternatively, what is the underlying mechanism that drives the deregulation process in China?

In order to answer these questions, we propose a model to highlight the effect of airline exit on airfare deregulation, where the regulator makes the decision regarding airfare deregulation by comparing the consumer welfare with and that without airfare caps. Without airfare caps, airlines are more likely to charge higher airfares, which may decrease consumer welfare and thus justify the continued imposition of caps. With airfare caps, airlines that do not earn satisfactory profits may choose to exit the market. When all airlines exit, the market is left un-served and the consumer surplus is reduced substantially. In particular, the probability of all airlines exiting a route becomes significant when the route is operated by a small number of airlines, which may prompt the regulator to remove the airfare caps to allow airlines serving the market to recoup their operating costs.

The deregulation mechanism characterized above is largely based on the public interest theory. 
In order to allow for the possibility of regulatory capture, we also integrate in the model the potential collusion among airlines to capture the regulator in order to remove airfare caps. The two different mechanisms through which the regulator decides whether to remove airfare caps help distinguish the two theories. Not only market size and collusion cost both have different implications for the probability of price deregulation, but also the two theories have different predictions on airlines' entry and exit behaviors post deregulation. After careful empirical tests of these predictions using two distinctive datasets, we find evidence more consistent with the public interest theory, rather than the regulatory capture theory.

Our study is relevant to two strands of literature. One strand of literature highlights two competing theories on regulation, with the public interest theory assuming a benign government intended to maximize consumer welfare, whereas the regulatory capture theory emphasizing the successful capture of the regulator by organized interest groups to optimize their own well-being. Empirically, while the emergence and long life-span of regulation are found to be consistent with the regulatory capture theory (Stigler, 1971; Peltzman, 1976; Becker, 1983; Djankov et al., 2002), researchers have observed that deregulation is more likely to serve public interest (MacAvoy and Schmalensee, 2013). The present paper contributes to this literature in two ways: Our theoretical model integrates both the public interest theory and the regulatory capture theory to explain the regulator's decision to deregulate; and the empirical part provides supportive evidence that public interest has been served during the deregulation process in China's airline industry, in line with existing findings regarding deregulation.

The other strand of literature relevant to our study is that on deregulation and competition in the airline industry (Borenstein and Rose, 2013). Because the deregulation process is transparent and swift in the United States, existing studies on the U.S. airline industry have largely treated the deregulation process as exogenous and thus have focused on the effects of deregulation on competition. In contrast, deregulation in China's airline industry has been a gradual and opaque process, granting us both the need and the possibility to investigate the causes of deregulation and the motives of the regulators. Our findings suggest a much richer set of interactions between deregulation and competition, where the cause-effect relation can go both ways.

To summarize, the main contribution of the paper is to examine the gradual process of deregulation in China's airline industry by exploring the potential mechanism through which insufficient 
competition leads to deregulation. As the lack of competition is an important feature in less developed economies, the study offers a new perspective on the deregulation process in developing countries. The paper is organized as follows: Section 2 reviews the history of price deregulation in China's airline industry and presents two seemingly contradictory patterns to be explained. Section 3 proposes a theoretical model on the deregulation process, which rationalizes the two patterns and integrates both the public interest theory and the regulatory capture theory. Section 4 first presents robust empirical evidence on the two patterns and then provides further evidence to distinguish the public interest theory and the regulatory capture theory, finding evidence more in line with the public interest theory. Section 5 provides results from various robustness tests, while the last section concludes. Proofs, summary statistics and additional test results are included in the appendices.

\section{Deregulation of Airfare Caps in China and Two Empirical Pat- terns}

In this section, we provide background information on airfare cap deregulation in the context of economic reforms in China, and present two seemingly contradictory patterns on how airfares and the deregulation of their caps relate to the number of airlines operating in the airline route.

\subsection{Airfare Deregulation and Economic Reforms in China}

Different from other modern economies where regulations are adopted to address issues related to market failures, China began its reforms in the late 1970s from a planned economy where regulation of the extreme form was the rule rather than the exception. Economic decisions including prices in all sectors were regulated to the greatest extent, mostly fixed with very small margins for adjustment. The process of deregulation has thus been a main feature throughout the reform era, and the reasons and timing for deregulation tend to follow the same logic and approach of economic reforms in China. While China's approach to reform can be characterized as a gradualist

one, where incremental changes are introduced when circumstances are deemed appropriate, the guiding principle for such reforms since 1992 has been, by and large, for the market to play an ever more important role in the process of price determination. As a result, we often observe deregulation 
implemented in stages, where additional market segments become deregulated gradually over time.

Thus in contrast to most other countries, where rate regulation is called for by some initial conditions that cause market failures and the disappearance of these conditions later justifies the removal of the price restrictions, China began its regulatory reforms in a planned economy with practically all prices invariably regulated. Consequently, the focus of research on regulatory reforms in China is to explore the process and determinants of deregulation rather than to study the initial conditions for introducing the regulation.

In the context of China's airline industry, which started operating shortly after the beginning of the reform era, the process of deregulation has been a gradual operation largely in the charge of the same government regulatory agency that had initiated and implemented the existing regulation, the Civil Aviation Administration of China (CAAC). Like the Civil Aeronautics Board (CAB), its U.S. counterpart, the CAAC has been the government agency in charge of both entry and rate regulations since the airline industry was first separated from the PLA Air Force in 1980. But unlike the $\mathrm{CAB}$, the CAAC had both regulated China's airline industry and managed its daily operations throughout the 1980s.

It was not until January 1987 when airports were separated from the management of the CAAC, and not until October 1993 when China Southern Airlines was established as the first airline company in modern China. As the airline company was still under the direct supervision of the CAAC regarding its operations, the separation of enterprise from government in the airline industry was not complete until 2002, when the 9 airline companies under the supervision of the CAAC at the time were restructured to form three airline groups: Air China, China Eastern Airlines, and China Southern Airlines, which have since performed their daily business operations independent of the $\mathrm{CAAC} \mathrm{D}^{1}$ And the CAAC was then formally restructured to serve as the regulatory agency of the airline industry.

The separation of enterprise from government was followed by the market entry deregulation stage, where restrictions regarding market entry have been gradually removed, and by 2010 only air routes connecting to Beijing, Shanghai, and Guangzhou require approval, whereas entry access

\footnotetext{
${ }^{1}$ Albeit financially independent, these airlines are all SOEs under the surveillance of the State-owned Assets Supervision and Administration Commission of the State Council (SASAC), which has the ultimate power to appoint their CEOs and monitor their financial performance. Presumably, the surveillance under the common agency allows them to conduct implicit collusion to a certain extent, a fact which we will explore in later sections to help test the regulatory capture theory.
} 
to other routes can be obtained through registration.

Shortly after the beginning of market entry deregulation, the main focus of the current studyrate deregulation, has been gradually introduced and implemented. The initial pricing mechanism in the Chinese airline industry followed the mainstream approach at the time, where airlines could only adjust their prices within a narrow price range around a base price set by a formula largely determined by operation costs, with the price floor and the price cap as fixed multiples of the base price $2^{2}$ The airfare deregulation process since then has involved the gradual expansion of the price range, including the eventual removal of all price floors in 2013, as well as airfare cap removals in four waves carried out at uneven intervals in 2004, 2013, 2014, and 2016, respectively, with price caps in additional air routes removed in each wave $3^{3}$

The timeline of airfare deregulation is depicted in Figure 1. While the number of routes deregulated in each wave varied substantially, the total scope of deregulation has been relatively limited, with only about $30 \%$ of airline routes having their airfare caps eliminated by 2017 , thirteen years after the first wave of elimination in 2004.

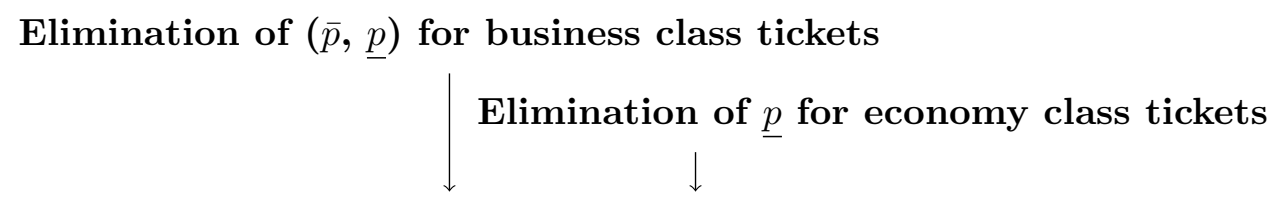

\begin{tabular}{crrrr} 
Mar. 2004 & Jun. 2010 & Oct. 2013 & Nov. 2014 & Nov. 2016 \\
\hline 1st wave (94 routes) & 2nd wave(31 routes) & 3rd wave(101 routes) & 4th wave(375 routes) \\
\hline
\end{tabular}

Elimination of $\bar{p}$ for economy class tickets

Figure 1: Timeline of airfare deregulation

Given the time frame of various regulatory reforms in the airline industry, the current paper will mainly study the recent period of 2013-2016. This will allow us to focus on rate deregulation without having to worry about changes in entry regulation or government intervention in airline companies' daily operations. $4^{4}$

\footnotetext{
${ }^{2}$ The current rule for determining the airfare caps is given in the Announcement on Further Improving Domestic Passenger Air Transportation Price Policies of 2014, with the following formulae for regular air routes and plateau routes, respectively: $\log _{\text {route distance } * 0.6} 150 *$ route distance $* 1.1$, and $\log _{\text {route distance }} 150 *$ route distance $* 1.3$. Between March 2004 and November 2014, the base price was given as route distance*0.75, while the minimum price was set at $55 \%$ of the base price between 2004 and October 2013, after which all price floors were removed.

${ }^{3}$ Price caps for business class tickets were eliminated in all routes in 2010 . While this policy change may have indirect effects on economy class ticket prices, it was implemented before our study period of 2013-2015.

${ }^{4}$ Although several rounds of airfare deregulation had been conducted before 2002, when the full separation of
} 
In stark contrast to the deregulation process in the U.S. airline industry, where the process is characterized by the fast pace and the independence of the related procedures. In particular, the Civil Aeronautics Board (CAB) in charge of regulating the airline industry was completely shut down in 1984, merely a few years after the passage of the Airline Deregulation Act in 1978. Aided by the fact that the deregulation took place through an explicit formal regulatory system independent of intervention from the previous regulator, most research on U.S. airline deregulation, which is among the most studied topics in the regulation literature, has been focused on the economic consequences of the deregulation process. Instead, the gradual and oftentimes opaque process of deregulation in China implies that it is worth exploring what factors explain the price cap removal in some routes earlier than in the others. And we will take up such a task in the current study.

The first place to start the investigation is the various government documents regarding the multiple rounds of airfare reforms ${ }^{5}$ According to these documents, the guidelines for China's airline industry reforms have been essentially the same since the first wave of airfare cap elimination in 2004. One of the top objectives for airline industry reforms including passenger airfare reforms is to serve public interest. In particular, as stated in Some opinions of the State Council on promoting the development of civil aviation industry of 2012, which has served as the guidelines for reforms in the airline industry, among the industry's second main task of "scientifically planning domestic air routes" ${ }^{6}$ is to implement the essential air service program, which is the reference to universal service obligation in China. $]^{7}$

As air travel is an important way to connect the remote and land-locked cities, a city's connection to the airline network not only decreases the cost to travel out of the city itself, it also contributes to the whole airline network connectivity. The spillover effects thus generated on other routes is the

enterprise from government was implemented, they were widely considered failures to be rectified by the reinstatement of price regulation. While it is beyond the scope of the current paper to explore the explanations for such failures, we think that the direct financial control by the government agency that simultaneously regulates the industry has introduced the soft budget problem to the airline companies, which have the incentive to maximize budget (i.e., operation costs) instead of profit.

${ }^{5}$ The documents include the Price Reform Plan for Domestic Passenger Air Transportation of 2004, the Announcement on Improving Domestic Passenger Air Transportation Price Policies of 2013, the Announcement on Further Improving Domestic Passenger Air Transportation Price Policies of 2014, and the Announcement on Issues Related to Deepening Price Reform for Domestic Passenger Air Transportation of 2016.

${ }^{6}$ The first main task of the civil aviation industry is to improve airport planning and construction.

${ }^{7}$ Specifically, the goals of the essential air service program include the following, according to the document: to strengthen the connection among national and regional air routes, to improve the connectivity and utilization of small and medium-sized airports, and to provide air travel services to more population by utilizing affordable aircrafts that satisfy safety standards in regions that are economically backward and geographically inaccessible. 
main justification for the universal service provision, because people in other cities can now more easily travel to other cities through the newly connected city. Another important consideration in airfare deregulation is the presence of competition from other transportation modes (such as high-speed rail, HSR), which implies short-distance routes with more inter-industry competition are more likely to be deregulated, according to the various documents referred to above.

While the objectives proclaimed in the various government documents suggest a process of deregulation motivated by public interest, the following facts imply other possibilities. First of all, still binding for 35\%-45\% of all tickets sold in our sample, depending on the purchase date, airfare caps continue to be an important constraint on airline profitability 8 Clearly, airlines prefer the elimination of airfare caps, which allows them to charge higher airfares but will lead to consumer welfare loss. Furthermore, the CAAC, which plays the most important role in determining the routes and pace of airfare cap removal, has shared a long history and has continued to have close relationship with the airlines it regulates, including frequent personnel exchange. Finally, the gradual and opaque features of the deregulation process also allows the strong possibility of regulatory capture. In fact, the empirical patterns we now turn to discuss next seem to confirm this possibility, i.e., the regulator may have been captured by the airlines.

\subsection{Patterns of Airfares and Airfare Cap Deregulation in China}

The importance of the price ceiling regulation can be demonstrated in table 1 and figure 1 , which give the proportions of airfares that are at the price ceiling among all posted ticket prices included in our data sample, among all prices by day of advance purchase, and among all prices by travel time of the day (in one-hour-intervals). Clearly, airfare caps are frequently binding: Over $38 \%$ percent of all prices have seen airfares hitting the price caps, while the percentage of prices with airfares hitting the ceiling ranges from $36 \%$ to $43 \%$, depending on the day of advance purchase, and ranges from $14 \%$ to $56 \%$, depending on the hour of the air travel.

Table 1: Proportions of ticket prices hitting airfare caps

\begin{tabular}{cccccc}
\hline & Whole sample & 3 -day & 7 -day & 14 -day & 21-day \\
\hline$\%$ (airfare caps) & $38.23 \%$ & $35.78 \%$ & $35.82 \%$ & $37.68 \%$ & $43.48 \%$ \\
\hline Data Sources: Our own calculation based on airfare data $(2007-2008)$.
\end{tabular}

\footnotetext{
${ }^{8}$ Airfare floors were completely removed in 2013 , as they had become largely non-binding by then due to increases in operation costs over the years. In our sample, only $1 \%$ of all tickets sold were at or below airfare floors.
} 


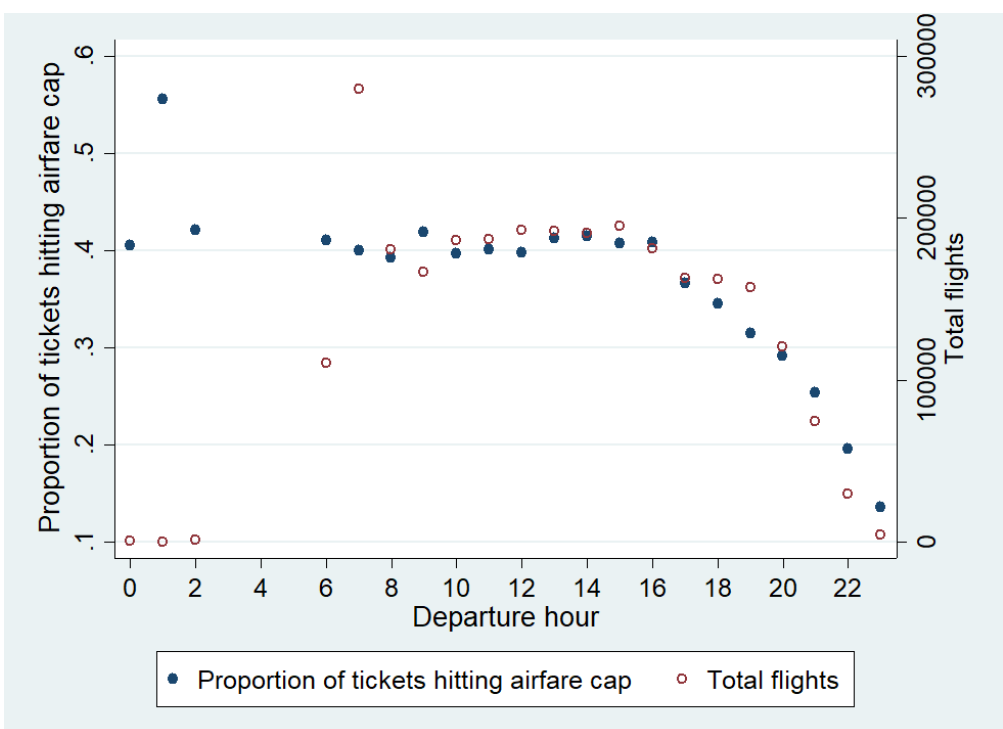

Data Sources: Our own calculation based on airfare data (2007-2008).

Figure 2: Departure hour and airfare caps

When further zeroing in on specific air routes, we find that only eight routes out of a total of 413 routes, all of which are short-distance routes, have never seen airfares reaching the price ceilings. For flights departing at 7am, the most popular time slot, only six routes have not seen price ceiling being hit? It is thus clear that the price ceilings are binding for a large part of the market, implying very meaningful constraints on the profit maximizing airlines.

Two patterns stand out when we investigate airfares and their caps among different airline routes, suggesting the possibility of regulatory capture, where airlines collude to influence the regulator to adopt policies to their liking. In particular, airfares tend to be lower in routes with more airlines, on the one hand; but on the other hand, the removal of the airfare cap (or deregulation) is more likely to be implemented in routes with fewer airlines.

Figure 3 shows that airfares are significantly lower in routes with more than four airlines and higher in routes with one airline. As the number of airlines increases, airfares generally decrease. Results in Section 4.2.1 will show that such a pattern is also invariant to departure time, which addresses the concern of dynamic pricing, and in addition the pattern is robust after taking into

\footnotetext{
${ }^{9}$ The first group of routes include those connecting Fuzhou and Xiamen, Hangzhou and Wenzhou, Shenyang and Dalian, Qingdao and Jinan, Chengdu and Chongqing, Guiyang and Chongqing, Ningbo and Shanghai, and Shanghai and Wenzhou, while the second group include those connecting Hangzhou and Wenzhou, Shenyang and Dalian, Chengdu and Chongqing, Guiyang and Chongqing, Ningbo and Shanghai, and Shanghai and Wenzhou. The second group includes fewer routes than the first group, because there are no flights for the specific time slot between Qingdao and Jinan or between Fuzhou and Xiamen.
} 
account of the distance effect.

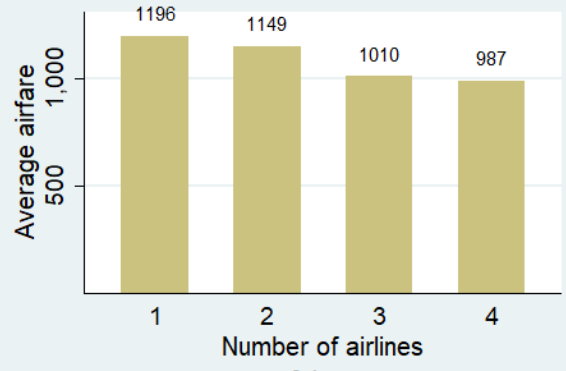

3days

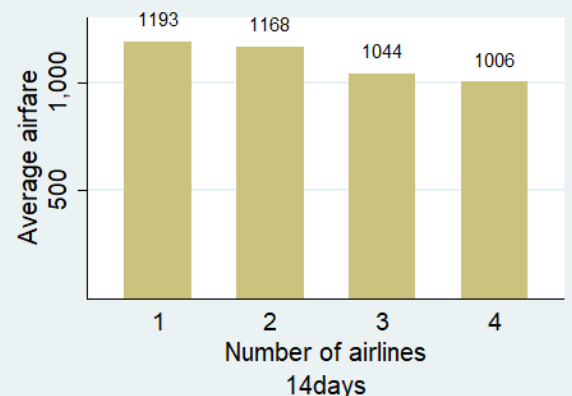

14days

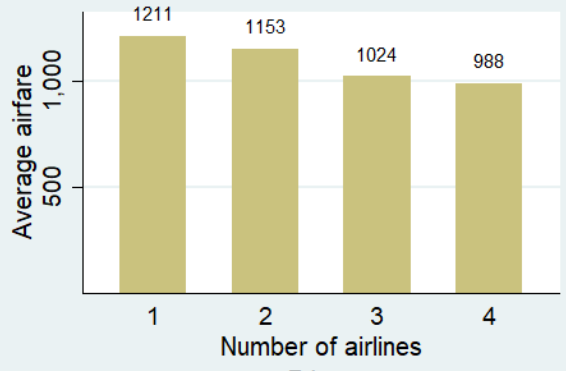

7 days

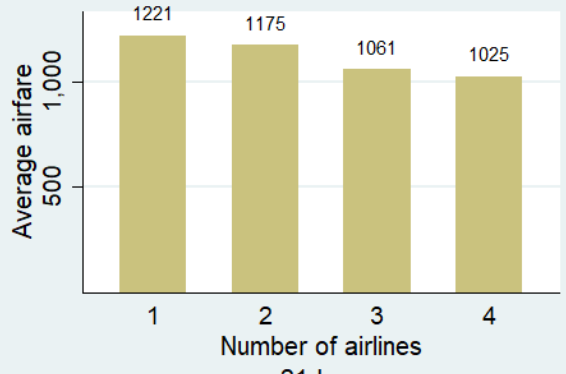

21days

Data Sources: Our own calculation based on airfare data (2007-2008).

Figure 3: Airfare and number of airlines

Although airfares are higher in routes with fewer airlines, implying more binding airfare caps, deregulation of airfare caps is more likely to be implemented in these same routes with fewer airlines. Figure 4 shows that $35.4 \%$ out of all deregulated routes are those with only a single airline whereas $31 \%$ among regulated airlines are routes with a single airline. The comparison between deregulated routes and regulated routes suggests that the deregulation of airfare caps is more skewed toward routes with fewer airlines, in particular in routes with one or two airlines. Table 2 shows the ratio between the proportion of deregulated routes operated by a given number of airlines and that of regulated routes operated by the same number of airlines. Apparently, the ratio is decreasing with the number of airlines operating in the route, which again suggests that the deregulation of airfare caps is more likely to be in routes with fewer airlines.

Table 2: Deregulation outcome

\begin{tabular}{llllllr}
\hline Number of airlines & 1 & 2 & 3 & 4 & 5 & $\geq 6$ \\
\hline $\begin{array}{c}\text { \% of deregulated routes } \\
\text { \% of regulated routes }\end{array}$ & 1.15 & 1.08 & 0.73 & 0.98 & 0.97 & 0.92 \\
\hline Data Sources: Our own calculation based on airfare data & $(2007-2008)$.
\end{tabular}




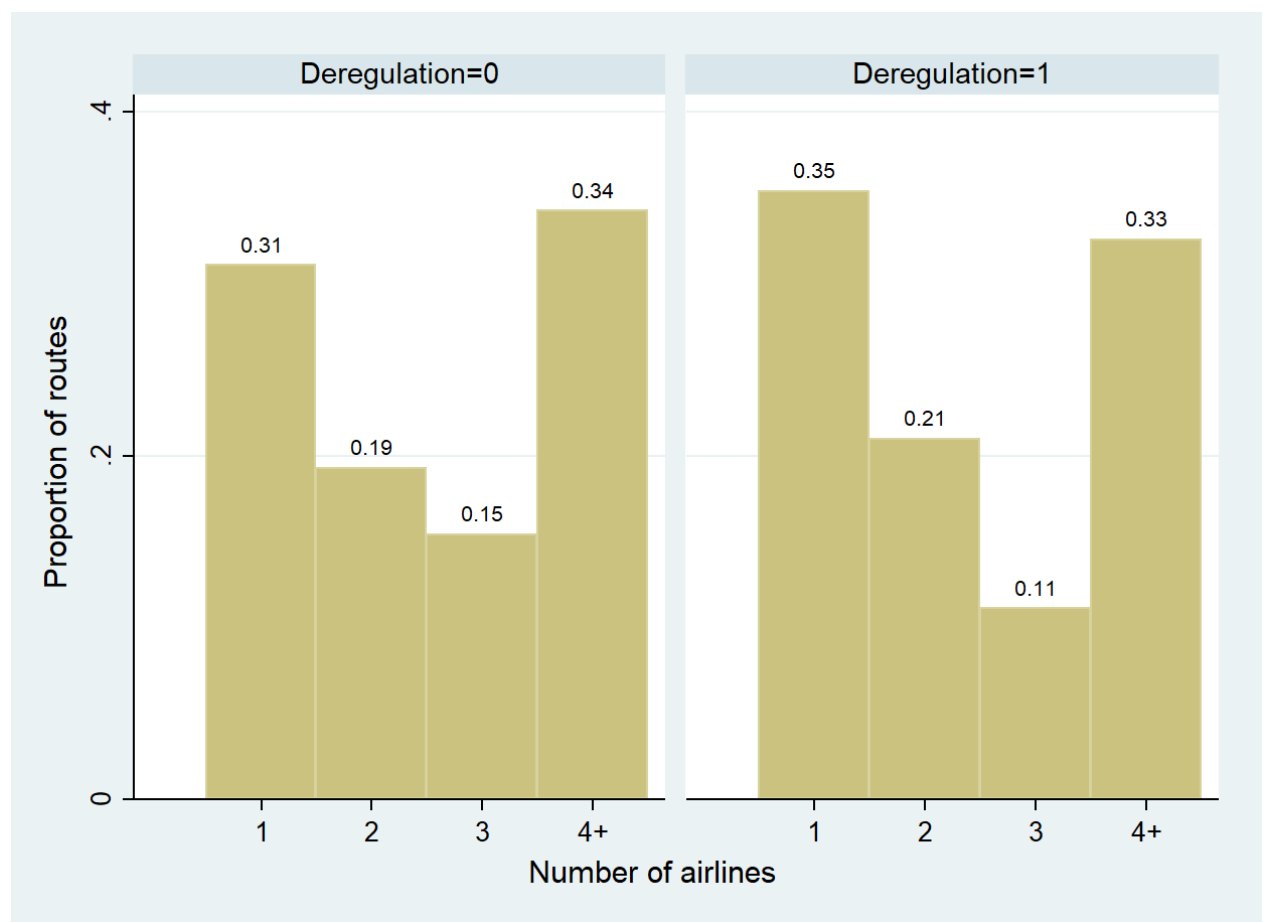

Data Sources: Our own calculation based on deregulation data (2013-2016).

Figure 4: Deregulation and number of airlines

A question thus naturally emerges: Why is the removal of airfare caps more likely in routes with fewer airlines if airfares are higher in these same routes? As airfare caps are more likely to be binding where airfares are higher, the observed pattern of deregulation seems to defeat the purpose of airfare caps to begin with, which is to prevent airlines from raising prices to harm consumer welfare. Or perhaps this is evidence that the regulator has been captured by airlines, despite the lofty objective of public interest protection as proclaimed in the various government documents? On the other hand, being one of the newest industries born at the early hours of China's economic reforms, the airline industry probably has the smallest vested interest group and thus the least danger of being captured, giving public interest the best chance to be served during the deregulation reforms.

Which of the two hypotheses above have more validity? This necessitates an investigation into the causes of deregulation and the motives of the regulator in China's airline industry. In particular, we look into two relevant theories, the public interest theory and the regulatory capture theory, by first building a theoretical model to explain the two seemingly contradictory patterns described above. We will also unveil the different mechanisms of the two theories and characterize 
the conditions under which the two theories can be distinguished. The empirical examination of the theoretical predictions is then conducted in Section 4, which is made possible by some newly available data.

\section{Theoretical Model}

In this section we outline a theoretical model, with the goal to simultaneously explain the two patterns relating airfares and their caps to the number of airlines operating in a route. After outlining the airline's optimization problem, we first consider the framework of the public interest theory, where the regulator makes the deregulation decision by comparing the consumer surplus with and that without airfare caps. With airfare caps, the airline might exit and leave the route un-served, which will substantially decrease consumer welfare, especially when a route has a single airline. Without airfare caps, the consumer surplus may decrease due to airfare hikes.

We then consider the regulator's decision-making based on the regulatory capture theory, where fewer airlines are more likely to collude and convince the regulator to remove the airfare cap, so they can charge higher prices. While the public interest theory highlights the mechanism of exit as a threat to consumer welfare, the regulatory capture theory emphasizes the potential collusion among airlines. Although the number of airlines operating in a route plays a key role for both theories, the mechanism in the public interest theory relies on the exit possibility, while that in the capture theory also depends crucially on other market structure features with influence on the feasibility of airline collusion. We derive three testable implications from the model to compare the two theories.

\subsection{Airlines' Decision-Making}

Unlike the hub-spoke structure in the U.S., the airline industry in China is characterized by mostly non-stop flights between two cities. We define a route that connects two cities as a market, where $J$ airlines are in operation and each of the airlines is indexed by $j \in\{1,2, \ldots, J\}$. Assume that the valuation of a representative customer (passenger) $i$ to travel by airline $j$ is $\theta_{j}$ and the airfare is $p_{j}$. The utility of the representative customer $i$ choosing airline $j$ is then:

$$
u_{i j}=\theta_{j}-p_{j}+\epsilon_{i j}
$$


where $\epsilon_{i j}$ denotes the individual idiosyncratic shock on utility. Suppose $\epsilon_{i j}$ follows type I extreme value distribution. The market share for airline $j$ is thus:

$$
s_{j}=\frac{\exp \left(\theta_{j}-p_{j}\right)}{1+\sum_{j} \exp \left(\theta_{j}-p_{j}\right)}
$$

The outside option is normalized to be 1 , which includes other modes of transportation. Suppose the total number of customers in the market is $N$, and the marginal cost for each customer is $c_{j}$. Airline $j$ 's expected profit thus becomes:

$$
\pi_{j}=\left(p_{j}-c_{j}\right) s_{j} N
$$

Under the current specifications, consumer surplus can be expressed as the expected utility from the choice set of the $J$ airlines as follows 10

$$
C S(p, J)=\ln \left[1+\sum_{j=1}^{J} \exp \left(\theta_{j}-p_{j}\right)\right] N
$$

To simplify the analysis, we focus on the symmetric case where all airlines are the same. The subscript $j$ can thus be omitted. Given other $(J-1)$ airlines' airfare $p^{*}$, if an airline sets airfare $p$ in competition, its market share is given as:

$$
\frac{\exp (\theta-p)}{1+\exp (\theta-p)+(J-1) \exp \left(\theta-p^{*}\right)}
$$

And the competitive equilibrium price $p^{*}$ satisfies the following proposition:

Proposition 1: Under the condition of $1<(p-c)<\frac{J}{J-1}$ for all $p$, the competitive airfare $p^{*}$ decreases with the number of airlines $J$.

Proof: See Appendix I.

Proposition 1 illustrates the relationship between the competitive airfare and the number of airlines operating in the market, where as more airlines compete with one another, the airfare

\footnotetext{
${ }^{10}$ This is the inclusive value (Trajtenberg, 1989)
} 
decreases. The intuition is straightforward as follows: On the one hand, airlines can increase airfare to reap more profit from each consumer that travels by air; On the other hand, airlines compete with one another to gain more customers by attracting the marginal customer that may choose other modes of transportation because of high airfares. As the number of airlines $J$ increases, the second effect becomes dominant so that airlines tend to set lower airfares with more competitors in the market.

In reality, we observe airfare fluctuates across airline and over time, such as the firm's dynamic pricing strategy and other price variations in different time slots. Since these factors are not the focus of our study, $p^{*}$ can be considered as the average price across airline overtime.

In the following sections, we will discuss the public interest theory and the capture theory separately to generate different testable implications.

\subsection{Regulator in the Public Interest Theory}

We now present the public interest theory in which the regulator makes the deregulation decision solely based on considerations of consumer surplus ${ }^{11}$ Guided by the empirical evidence, the airfare cap $\bar{p}$ is assumed to be binding in practice such that $\bar{p}<p^{*}$, airlines prefer the removal of airfare caps so that they can set higher airfares.

The timing is as follows: The regulator first makes the price ceiling removal decisions based on the number of airlines in each route and the consumer surplus shock $\bar{\zeta}$ (in cases with airfare caps) and $\zeta$ (in cases without airfare caps), both of which follow the same distribution $\Phi: \zeta \sim \Phi$ and $\bar{\zeta} \sim \Phi$; After the removal decisions are made, the profit shock $\xi_{j}$ is realized on airline $j$, which then determines the exit decision. As $\xi_{j}$ is i.i.d. across airlines, following the same distribution $G: \xi_{j} \sim G$, in routes with airfare caps each airline independently exits with probability $k \underbrace{12}$ The probability of the airline remaining in the market is thus $(1-k)$.

Suppose $m$ denotes the number of airlines staying in the market. The expected consumer surplus without the removal of the airfare cap, $\bar{W}^{P I}$, is thus given as the weighed sum of $C S(\bar{p}, m)$, which

\footnotetext{
${ }^{11}$ In general, the regulator is to maximize the social surplus, which depends on both consumer surplus and producer surplus. We assume away producer surplus in the objective function of the regulator to highlight the key mechanism of public interest theory. But the main results can be easily generalized to cases when the tradeoff between the producer surplus and the consumer surplus is also taken into consideration, as long as the regulator can derive additional capture benefit from in the capture theory in comparison to the public interest theory.

${ }^{12}$ The probability $k$ can be derived from the comparison between the realized profit $\pi+\xi$ and the fixed cost $f$. A firm exits if $\pi+\xi<f$, which implies an exit probability of $k=G(f-\pi)$.
} 
is the consumer surplus when $m$ airlines stay in the market:

$$
\bar{W}^{P I}=\sum_{m=0}^{J} C_{J}^{m}(1-k)^{m} k^{J-m} C S(\bar{p}, m)-k^{J} \Delta+\bar{\zeta},
$$

where $C_{J}^{m}(1-k)^{m} k^{J-m}$ denotes the probability of $m$ out of $J$ airlines staying in the market. If all airlines exit, leaving the market un-served, the consumer surplus in the market becomes 0: $C S(p, 0)=0$. In addition, if the market is un-served, with the probability $k^{J}$, an extra consumer surplus loss, $\Delta$, is generated from routes connected to the un-served market because of the shrinkage in the airline network span, which is the negative effect on connectivity to other market. Thus, $\Delta$ alternatively denotes the value of universal service obligation in the sense that an un-served market creates negative externality to the other connected markets.

In contrast, if the regulator eliminates the airfare cap, the airfare becomes $p^{*}$ so that no airline exits due to no restriction against airfare hikes ${ }^{13}$ Correspondingly, the expected consumer surplus without airfare caps, $W^{P I}$, is given as:

$$
W^{P I}=C S\left(p^{*}, J\right)+\zeta
$$

The regulator, who cares about consumer surplus, makes the decision on whether to remove the airfare cap by comparing the surplus with and that without the cap:

$$
\max \left\{\bar{W}^{P I}, W^{P I}\right\}
$$

The following proposition shows that the regulator is more likely to eliminate the airfare cap when the number of airlines operating in a market, $J$, is smaller, and when the market size, $N$, is smaller.

Proposition 2: As long as $k$ is not too large, the regulator in the public interest theory is more likely to eliminate the airfare cap in markets with fewer airlines and smaller market size.

\section{Proof: See Appendix I.}

\footnotetext{
${ }^{13}$ In practice, airlines may still exit market even if airfare caps are removed. But the analysis applies as long as airfare cap removal leads to less exiting.
} 
Proposition 2 states that the removal of the airfare cap is more likely to be implemented in routes with fewer airlines and smaller market size. The intuition for the proposition is as follows: While the consumer surplus with airfare caps is higher than that without caps when the number of airlines operating in a market remains fixed, the reduction in service variety due to airline exits at the presence of airfare caps will reduce such a gap. And as the number of airlines becomes sufficiently small, the lower service variety becomes more important; and in the extreme case of all airlines exiting, the market becomes un-served, which creates an additional welfare loss $\Delta$ due to the lower connectivity for other routes. As the probability of all airlines exiting from a given market is $k^{J}$, a market with fewer airlines is more likely to be un-served. Thus, the regulator here can be viewed as pursuing public interest by ensuring more markets remain served by at least one airline, or alternatively, a version of the universal service obligation. As can be seen, the key mechanism in the public interest model here is the possibility of all airlines exiting from under-served markets where the number of airlines is small. In addition, as long as the probability of exiting is not too large, larger market size scales up more the consumer welfare with airfare cap as opposed to that without airfare cap, if the number of airlines are the same.

\subsection{Regulator in the Regulatory Capture Theory}

The competing view of what motivates the regulator is the regulatory capture theory, which we now turn to discuss in detail. While the public interest theory highlights the mechanism of airlines exiting, the regulatory capture theory emphasizes the potential collusion among airlines to capture the regulator to remove the airfare cap. The theory also generates the same patterns observed above, because fewer airlines might collude more easily to capture the regulator. The timing is as follows: Airlines first collude to capture the regulator by offering private benefit $\Lambda$; Then the regulator makes the removal decisions based on total social surplus, which depends on both consumer surplus, the private capture benefit and the realized consumer welfare shocks $\bar{\eta}$ and $\eta$ that independently follow the same distribution $S: \bar{\eta} \sim S$ and $\eta \sim S$.

Specifically, the regulator compares total surplus with and that without the airfare cap as follows:

$$
\max \left\{\bar{W}^{R C}, W^{R C}\right\}
$$


where $\quad \bar{W}^{R C}=C S(\bar{p}, J)+\bar{\eta}, \quad$ and $\quad W^{R C}=C S\left(p^{*}, J\right)+\Lambda+\eta$.

Furthermore,

$$
\Lambda=\lambda(J, \chi) N
$$

denotes the capture benefit to the regulator from the airfare cap removal, which is proportional to market size $N$, and also depends on the number of airlines $J$ as well as other market structure features, captured by $\chi$, with a higher $\chi$ implying easier collusion. Since $\lambda$ depends on both the number of airlines $J$ and the market structure feature $\chi$, we have:

$$
\frac{\partial \lambda(J, \chi)}{\partial J}<0, \quad \frac{\partial \lambda(J, \chi)}{\partial \chi}>0
$$

It suggests both a larger number of airlines and a market structure more difficult for collusion generates a smaller amount of capture benefit. Therefore, we have the following proposition, which will allow us to distinguish the public interest theory and the regulatory capture theory:

Proposition 3: Under the condition that $\lambda$ is sufficiently large, the regulator in the regulatory capture theory is more likely to eliminate the airfare cap in routes with fewer airlines, less difficulty in collusion and larger market size.

Proof: See Appendix I.

The rationale behind the proposition is the following: In the capture theory, the regulator not only considers consumer welfare, but also takes into account of the capture benefit when making the removal decision. A larger number of airlines and a market structure more difficult for collusion will imply a smaller amount of capture benefit from the airfare cap removal to capture the regulator, thus the regulator is less likely to remove airfare caps in such markets. By contrast, since the capture benefit is proportional to market size, the regulator is more likely to remove airfare cap in larger markets, if it is sufficiently large. 


\subsection{Distinguishing the Public Interest Theory and the Regulatory Capture The- ory}

Based on the discussion above, while both theories predict that the number of airlines is negatively associated with airfares and the likelihood of airfare cap removal, the two theories rely on different mechanisms through which deregulation decisions are made: While the public interest theory highlights the option to exit as a potential threat to reduce consumer surplus, the regulatory capture theory emphasizes the potential collusion among airlines. Consequently, we can explore the relevance of the two competing theories by deriving testable hypotheses from the two propositions regarding the roles of market size, market structure and firm entry/exit. In particular, we outline the three pairs of testable hypotheses as follows:

H1a (Market Size): According to the public interest theory, airfare caps are less likely to be removed in routes with larger market size.

H1b (Market Size): According to the regulatory capture theory, airfare caps are more likely to be removed in routes with larger market size.

H2a (Market Structure): According to the public interest theory, the market structure features $\chi$ that lead to easier collusion do not affect the deregulation decisions.

H2b (Market Structure): According to the regulatory capture theory, the market structure features $\chi$ that lead to easier collusion are positively associated with the probability of airfare cap removal.

H3a (Exit/Entry): According to the public interest theory, it is less likely to have all airlines exit if airfare caps are removed in the route, but the removal of airfare caps does not affect entry or even discourage entry.

H3b (Exit/Entry): According to the regulatory capture theory, the removal of airfare caps encourages entrants into the affected route.

While the first two sets of hypotheses follow easily from the propositions, the reasoning for the differences in market exit/entry between the two theories is as follows: According to the capture 
theory, the airfare cap removal makes the market more lucrative, whereas the public interest theory predicts that the market will be barely profitable even after the price ceilings have been abolished. In the following section, we will test the these theoretical predictions empirically.

\section{Empirical Analysis}

In this section, we first present robust empirical evidence for the two seemingly contradictory patterns, for which both the public interest theory and the regulatory capture theory can provide explanations. To distinguish the different mechanisms in the two theories, we then offer empirical findings on the three hypotheses to explore the impact of market size and additional market structure features, as well as the patterns related to firm exit/entry behaviors. And we find evidence more in line with the public interest theory.

\subsection{Data Description}

Before presenting the evidence, let us introduce the data. Airfare caps in China's airline industry were set by the regulator based on per kilometer operating cost till 2002, when the industry began to undergo gradual transition from having all airfares highly regulated to letting a significant portion of airfares determined by the market. The first wave of airfare cap eliminations was implemented in 94 routes in 2004, which allowed airfares in those routes to be adjusted through market competition. The second and third waves of airfare cap eliminations were implemented in 2013 and 2014, when the airfare caps in 31 and 101 routes were deregulated, respectively. In 2016, the fourth wave of airfare cap eliminations was carried out in 375 routes. In addition, airfares in a few routes were deregulated in-between different waves. By the end of 2016, 677 routes out of 2370 routes have seen their airfare caps eliminated. Although it has been 13 years since the first wave of airfare cap eliminations, the deregulated routes still only account for less than $30 \%$ of total routes, highlighting the gradualist approach to deregulation in China.

To explore the driving forces of airfare cap deregulation, we employ two distinctive datasets in this study. The first dataset consists of flight information scrapped from one of the largest online travel agencies in China, www.elong.com, covering the period from May 2007 to August 2008 for 413 routes connecting the largest 30 cities in China. The dataset is used to investigate the relationship 
between airfare and the number of airlines operating in a route. For each flight in the sample we have information on carrier, departure time, flight number and airfare. In particular, information on the actual purchase price for economy class plane tickets is collected, which varies with the time and day of the purchase. While the exact time of the ticket purchase is determined by the time of the scraping, the data collection has been implemented to include, for each flight, one airfare on each of the following purchase day in advance of departure: 21 days, 14 days, 7 days, and 3 days.

Table 3: Summary statistics for airfare data (2007-2008)

\begin{tabular}{|c|c|c|c|c|c|c|}
\hline & \multicolumn{2}{|c|}{ Whole sample } & \multicolumn{2}{|c|}{$J \leq 2$} & \multicolumn{2}{|c|}{$J \geq 3$} \\
\hline & mean & s.d. & mean & s.d. & mean & s.d. \\
\hline Airfare (RMB) & 955.4 & 419 & 1099 & 471.4 & 935.7 & 407.4 \\
\hline 1(airfare cap) & 0.382 & 0.486 & 0.393 & 0.488 & 0.381 & 0.486 \\
\hline Obs. & 273 & 820 & 328 & & 240 & 159 \\
\hline
\end{tabular}

Table 3 presents the summary statistics for the airfare data. As can be shown, airfares in routes served by fewer airlines tend to be higher, and the proportion of airfares hitting the price ceiling also tends to be higher in such routes, again consistent with the empirical patterns discussed earlier. There were 1216 domestic air routes in 2007, including 48 routes that connect inland Chinese cities to Hong Kong or Macao. While 146 inland cities had regular flights connecting to them in 2007, the largest 30 airports accounted for about $88.27 \%$ of the total throughput and the most popular 300 routes accounted for over $60 \%$ of the total passenger volume. As our data sample includes airfare information on all flights connecting the top 30 airports, it covers the vast majority of passenger air travels in China and is thus a highly representative sample of all passenger airfares.

The second dataset, Deregulation Data, is constructed on the flight time-tables from the Civil Aviation Administration of China (CAAC) for all regular flights during 2013-2016, which covers more than $80 \%$ of all routes from 2013 to 2016, with the remaining routes served only by temporary flights. The flight time-table data can be used to calculate the number of airlines operating in each route at any given time, which, when supplemented with the airfare cap deregulation decision information on all routes since 2012, allows us to examine the relationship between the number of airlines and the airfare cap deregulation outcome.

Table 4 gives the descriptive statistics for the main variables used in our deregulatoin inves- 
tigation, corresponding to the whole sample, for the deregulated routes, and the non-deregulated routes, respectively. As shown in the table, where $H S R$ and distance indicate whether there is direct high-speed rail connection between the two cities defining the route and the distance of the route, whereas $\ln G D P, \ln g d p$, and $\ln p o p$, denote the total GDP, GDP per capita, and population (all in logs, measured as the geometric mean of the two cities defining the route), deregulated routes are more likely to have direct HSR connection and shorter distance, as stated in the various government documents, but the cities do not exhibit much difference in their economic and population sizes. The various city level data are obtained from City Statistical Yearbooks of China (2013-2016).

Table 4: Summary statistics for deregulation data (2013-2016)

\begin{tabular}{cccccccccc}
\hline & \multicolumn{3}{c}{ All routes } & \multicolumn{3}{c}{ Deregulated Routes } & \multicolumn{3}{c}{ Non-deregulated Routes } \\
& mean & s.d. & obs. & mean & s.d. & obs. & mean & s.d. & obs. \\
\hline HSR & 0.105 & 0.307 & 6984 & 0.304 & 0.461 & 601 & 0.086 & 0.281 & 6383 \\
distance & 1234 & 641.2 & 6984 & 541.5 & 190.2 & 601 & 1299 & 630.1 & 6383 \\
$\ln$ GDP & 16.87 & 0.903 & 5054 & 17.02 & 1.011 & 438 & 16.86 & 0.891 & 4616 \\
$\ln$ gdp & 11.32 & 0.612 & 5054 & 11.44 & 0.643 & 438 & 11.31 & 0.608 & 4616 \\
$\ln$ pop & 5.544 & 0.574 & 5054 & 5.578 & 0.599 & 438 & 5.541 & 0.572 & 4616
\end{tabular}

Data Sources: CAAC flight time-tables, deregulation announcements, and City Yearbooks of China (2013-2016).

As our airfare sample and the information constructed using the CAAC flight time-tables that both exclude the less popular air routes, one may be concerned with the potential sample selection biases introduced in the study. We will address these issues in Section 5.1, where evidence will be provided to show that the potential selection biases further strengthen rather than weaken our findings.

\subsection{Number of Airlines versus Airfares and Cap Deregulation}

\subsubsection{Number of Airlines versus Airfares}

First, we turn to the relationship between the number of airlines and airfare level in a route. Although the negative relationship holds at first glance, we need to control for other explanatory variables such as route distance and market demand, by adopting the following estimation specification:

$$
\ln p_{r j d h}=\beta J_{r d}+D+\gamma_{j}+\mu_{d}+\delta_{h}+\epsilon_{r j d h},
$$


where the dependent variable is the logarithm of airfare, $\ln p_{\text {ridh }}$, and $r, j, d, h$ denote the route, the airline, the date, and the hour within a day of the flight, respectively. $D$ is a set of dummies that represents the day of purchase in advance of departure, which is intended to captures the dynamic pricing effect. The main variable of interest is $J_{r d}$, which denotes the number of airlines operating in route $r$ on day $d{ }^{14}$

Table 5: Airfare versus number of airlines

\begin{tabular}{|c|c|c|c|c|c|}
\hline & \multicolumn{4}{|c|}{$\ln p_{r j d h}$} & \multirow{2}{*}{$\begin{array}{c}\mathbf{1} \text { (airfare cap) } \\
(5)\end{array}$} \\
\hline & (1) & $(2)$ & $(3)$ & (4) & \\
\hline$J_{r d}$ & $\begin{array}{c}-0.064^{* * *} \\
(0.016)\end{array}$ & $\begin{array}{c}-0.037^{* * *} \\
(0.007)\end{array}$ & $\begin{array}{c}-0.060^{* * *} \\
(0.009)\end{array}$ & & $\begin{array}{c}-0.029^{* * *} \\
(0.004)\end{array}$ \\
\hline$J_{r d}^{\prime}$ & & & & $\begin{array}{c}-0.063^{* * *} \\
(0.009)\end{array}$ & \\
\hline $\ln d i s_{r}$ & & $\begin{array}{c}0.650^{* * *} \\
(0.020)\end{array}$ & & & \\
\hline 3-day & $\begin{array}{c}0.010^{* * *} \\
(0.004)\end{array}$ & $\begin{array}{c}0.000 \\
(0.003)\end{array}$ & $\begin{array}{c}-0.01 \\
(0.008)\end{array}$ & $\begin{array}{c}0.001 \\
(0.008)\end{array}$ & $\begin{array}{c}0.010^{* *} \\
(0.004)\end{array}$ \\
\hline 14-day & $\begin{array}{c}0.016^{* * *} \\
(0.002)\end{array}$ & $\begin{array}{c}0.015^{* * *} \\
(0.001)\end{array}$ & $\begin{array}{c}0.012 \\
(0.015)\end{array}$ & $\begin{array}{c}0.016 \\
(0.015)\end{array}$ & $\begin{array}{c}0.001 \\
(0.005)\end{array}$ \\
\hline 21-day & $\begin{array}{c}0.046^{* * *} \\
(0.003)\end{array}$ & $\begin{array}{c}0.048^{* * *} \\
(0.003)\end{array}$ & $\begin{array}{c}0.053^{* * *} \\
(0.008)\end{array}$ & $\begin{array}{c}0.056^{* * *} \\
(0.008)\end{array}$ & $\begin{array}{c}0.049^{* * *} \\
(0.005)\end{array}$ \\
\hline Fixed effects & $\gamma_{j}, \mu_{d}, \delta_{h}$ & $\gamma_{j}, \mu_{d}, \delta_{h}$ & $\gamma_{j r}, \mu_{d}, \delta_{h}$ & $\gamma_{j r}, \mu_{d}, \delta_{h}$ & $\gamma_{j r}, \mu_{d}, \delta_{h}$ \\
\hline$R^{2}$ & 0.212 & 0.668 & 0.574 & 0.574 & 0.540 \\
\hline Obs. & & & 273182 & & \\
\hline
\end{tabular}

The results are provided in table 5, where different columns correspond to various specifications and all show negative and significant correlations between the number of airlines and airfare. Column (1) strictly follows model (1) above, including airline fixed effects $\gamma_{j}$, as well as date effect, $\mu_{d}$, and the hour effect within a day, $\delta_{h}$, both of which help capture effects of heterogeneous demand that varies with time (by day and by hour). In column (2), we further control for the route distance to obtain a smaller negative coefficient of the number of airlines on airfare, but the effect remains statistically significant.

Since air routes connecting hub airports tend to have larger numbers of flights and may exhibit different patterns, in columns (3) and (4) we control for airline-route fixed effects, $\gamma_{j r}$, which should also capture the route distance effect and much of the quality difference in air travel. To address the concern of whether the estimates are sensitive to the inclusion of airlines with very small market

\footnotetext{
${ }^{14} \mathrm{An}$ airline is defined as serving route $r$ as long as it offers flights on any day(s) in a month.
} 
shares, we recalculate the number of airlines by excluding airlines with market shares less than 10\%: $J_{r d}^{\prime}$. The results remain robust and are presented in column (4).

In addition, we use an indicator function $\mathbf{1}$ (airfare cap) as the independent variable on the LHS to denote whether the airfare cap has been hit, instead of the actual airfare, with results given in column (5). This approach allows us to better account for the effect of distance for the following reason: While the distance factor is the major determinant of the actual airfare cap when it is set by the CAAC for each air route, the probability of hitting the airfare cap is independent of the route distance.

All estimates produce the consistent pattern that the number of airlines is negatively associated with airfare. Furthermore, the estimated effects of the dummies $D$ suggest the presence of the "J curve" in the sense that 21-day and 3-day advance purchases exhibit higher airfares than 7-day advance purchases. To further address the concern of dynamic pricing, We also conduct robustness checks to separately examine the airfares by the days of advance purchase and similar results are preserved (see Appendix II) ${ }^{15}$

\subsubsection{Number of Airlines versus Airfare Cap Deregulation}

We now turn to the relationship between deregulation outcome and the number of airlines operating in an air route. Similar to the section above, despite the negative relationship observed at first glance, we need to control for additional explanatory variables that may also impact the deregulation outcome. Thus the following specification is used to explore the relationship more carefully:

$$
d_{r t}=\beta J_{r t}+\delta_{t}+\alpha_{r}+\epsilon_{r t}
$$

where $r, t$ denotes the route and wave, respectively, and $d_{r t}$ is a dummy that denotes the implementation of airfare cap deregulation for route $r$ at wave $t$, i.e., $d_{r t}=1$ denotes a route where airfare caps have been removed during deregulation of wave $t$, whereas $d_{r t}=0$ denotes a route still subject to the airfare cap restriction. $J_{r t}$ remains the variable of interest, and its coefficient $\beta$ allows us to

\footnotetext{
${ }^{15}$ One may still be concerned with the influence of omitted variables. For example, the aggregate demand in a market may be positively associated with the number of airlines operating in the route, $J$, thus introducing bias into the estimation. But if the conjecture holds, we have $\operatorname{Cov}\left(J_{r m}, \epsilon_{r j d h}\right)>0$. But since $\operatorname{plim} \widehat{\beta_{O L S}}=\beta+\operatorname{Corr}\left(J_{r m}, \epsilon_{r j d h}\right) \frac{\sigma_{\epsilon}}{\sigma_{J}}$, our estimate will be an upper bound, giving more support that the true value of the parameter of interest is negative, i.e., $\beta<0$.
} 
empirically test the predictions from the theoretical model. Because $d_{r t}$ is irreversible in the sense that once removed the airfare cap in a route will not be imposed again, we drop those routes that have been deregulated from the estimation after the deregulation takes place.

Table 6: Deregulation versus number of airlines

\begin{tabular}{|c|c|c|c|c|}
\hline & \multicolumn{4}{|c|}{$d_{r t}$} \\
\hline & (1) & $(2)$ & $(3)$ & $(4)$ \\
\hline$J_{r t}$ & $\begin{array}{c}-0.027^{* * *} \\
(0.005)\end{array}$ & $\begin{array}{c}-0.011^{* * *} \\
(0.003)\end{array}$ & & $\begin{array}{c}-0.009^{* *} \\
(0.003)\end{array}$ \\
\hline$J_{r t}^{\prime}$ & & & $\begin{array}{c}-0.013^{* * *} \\
(0.004)\end{array}$ & \\
\hline$H S R_{r t}$ & & $\begin{array}{c}0.087^{* * *} \\
(0.018)\end{array}$ & $\begin{array}{c}0.085^{* * *} \\
(0.018)\end{array}$ & $\begin{array}{c}2.474^{* * *} \\
(0.312)\end{array}$ \\
\hline$H S R_{r t} * \ln$ distance $_{r}$ & & & & $\begin{array}{c}-0.344^{* * *} \\
(0.043)\end{array}$ \\
\hline dis600* year14 & & $\begin{array}{c}0.286^{* * *} \\
(0.043)\end{array}$ & $\begin{array}{c}0.287^{* * *} \\
(0.044)\end{array}$ & $\begin{array}{c}0.282^{* * *} \\
(0.043)\end{array}$ \\
\hline dis $800 *$ year 16 & & $\begin{array}{c}0.739 * * * \\
(0.030)\end{array}$ & $\begin{array}{c}0.741^{* * *} \\
(0.030)\end{array}$ & $\begin{array}{c}0.697^{* * *} \\
(0.033)\end{array}$ \\
\hline$\delta_{t}, \alpha_{r}$ & YES & YES & YES & YES \\
\hline$R^{2}$ & 0.169 & 0.561 & 0.553 & 0.574 \\
\hline Obs. & 4503 & 4503 & 4503 & 4503 \\
\hline
\end{tabular}

Column (1) in table 6 presents estimation results based on the above specification, showing a negative and significant relationship between the number of airlines operating in a route and the probability of airfare cap removal in the route. In addition, we take into account of the following facts: Air routes with short distances directly compete with high-speed railway, and in year 2014 and year 2016 the airfare cap deregulation was specifically targeted at those routes with distances below $600 \mathrm{~km}$ and $800 \mathrm{~km}$ for this reason.

Specifically, we control for $H S R_{r t}$, an indicator of whether the pair of cities on the route are connected by high-speed railway, as well as the interaction terms of short-distance indicators and deregulation wave indicators. Column (2) gives the estimation results when controlling for these additional effects. Relative to the results in column (1), the number of airlines has a smaller effect that remains negative and statistically significant. To address the potential impact of small airlines, we again recalculate the number of airlines by excluding airlines with market shares less than $10 \%$. The results are presented in column (3), giving similar patterns 16

\footnotetext{
${ }^{16}$ We also use a set of dummies instead to indicate each particular number of airlines operating in a route to rerun
} 
Finally, column (4) further controls for the interaction term between HSR and route distance (in $\operatorname{logs})$. The negative and significant coefficient for $H S R_{r t} * \ln$ distance $_{r}$ implies that the existence of HSR is correlated with a larger increase in airfare cap removal probability in shorter routes, which is consistent with the previous finding that HSR imposes more fierce competition with air traffic in short-distance routes and thus makes air demand more elastic (Zhang et al. 2017).

In summary, after careful examination of data, we find robust evidence for two patterns relating airfares and their caps to the number of airlines operating in an air route. And these patterns are consistent with predictions from both the public interest theory and the regulatory capture theory. In the following section, we explore the specific mechanisms that generate these patterns and further rely on the empirical findings to distinguish the two models.

\subsection{Explaining Airfare Cap Deregulation}

While both the capture theory and the public interest theory generate the same predictions regarding how prices and deregulation outcomes relate to the number of airlines, the distinction between the two models lies in the different mechanisms through which the relationship is established. Consequently, we can explore the relevance of the two models by testing the three hypotheses outlined in Section 3.4.

While both the capture theory and the public interest theory generate the same predictions regarding how prices and deregulation outcomes relate to the number of airlines, the distinction between the two models lies in the different mechanisms through which the relationship is established. First, the market size is negatively correlated with the likelihood of airfare cap deregulation in the public interest theory whereas the capture theory predicts the opposite relationship. Second, while the various market structure features that increase collusion difficulty (as captured in $\chi$ ) are negatively associated with the probability of airfare cap removal in the regulatory capture model, they do not affect the deregulation decision according to the public interest theory. Third, the public interest theory highlights potential airline exits as the key mechanism for generating the predicted patterns, thus it is less likely to have all airlines exit if airfare caps are removed in the route, whereas the capture theory is silent in this regard. Furthermore, we do not expect more

the estimations. Again, similar patterns are obtained, showing that the probability of deregulation decreases with the number of airlines. The results are presented in Appendix III. 
entry in those markets with airfare cap removal according to the public interest theory, because the increase profitability through airfare cap removals is only enough to prevent exit, but not enough to attract new entry. However, the removal of airfare cap, according to the capture theory, is more likely to attract airlines entry into the market because the market becomes more profitable.

\subsubsection{Testing Hypothesis H1: Role of Market Size}

First, we examine the hypothesis on the relationship between market size and the decision of airfare cap deregulation (H1), using the following specification:

$$
d_{r t}=\beta J_{r t}+\theta N_{r t}+\delta_{t}+\alpha_{r}+\epsilon_{r t}
$$

The public interest theory predicts the likelihood of airfare deregulation to be negatively correlated with market size (H1a), whereas the capture theory predicts a positive correlation (H1b). We use two sets of measures on market size $N_{r t}$ : (1) total GDP $(\ln G D P)$ and (2) GDP per capita $(\ln g d p)$ and population size $(\ln p o p)$, which are all measured as the geometric mean of the two cities connected by the air route.

Table 7: Market size and deregulation (H1)

\begin{tabular}{ccc}
\hline & \multicolumn{2}{c}{$d_{r t}$} \\
& $-0.011^{* * *}$ & $-0.011^{* * *}$ \\
& $(0.004)$ & $(0.004)$ \\
$J_{r t}$ & $0.051^{* *}$ & \\
$1($ small $\ln G D P)$ & $(0.023)$ & \\
& & 0.011 \\
$1($ small $\ln g d p)$ & & $(0.027)$ \\
& & 0.030 \\
$1($ small $\ln$ pop $)$ & & $(0.041)$ \\
\hline Other Controls & YES & YES \\
$\delta_{t}, \alpha_{r}$ & YES & YES \\
\hline$R^{2}$ & 0.067 & 0.067 \\
Obs. & 3349 & 3349
\end{tabular}

Notes: Other control variables include $H S R_{r t}$, dis600* year 14 , and dis $800 *$ year 16 .

$* *$, ** and $*$ denotes $1 \%, 5 \%$ and $10 \%$ significance level. All errors are clustered at route level.

The estimates in table 7 consistently show that the markets experiencing airfare deregulation are not "more attractive" with higher GDP and more population. $1($ small $\ln G D P), 1($ small $\ln g d p)$ and $1($ small $\ln$ pop $)$ denote whether the route ranks at the lowest quartile of total GDP, GDP per 
capita and population among all routes in that year, respectively. These patterns are inconsistent with the prediction of the capture theory, but could be in line with the public interest theory, as removing airfare caps in markets with smaller market size are more likely to yield welfare gains.

\subsubsection{Testing Hypothesis H2: Role of Collusion Cost}

Second, we examine the hypothesis on the relationship between market structure features and the decision of airfare cap deregulation (H2), with the specification set as follows:

$$
d_{r t}=\beta J_{r t}+\psi \chi_{r t}+\delta_{t}+\alpha_{r}+\epsilon_{r t}
$$

where $\chi_{r t}$ is the set of market structure features that potentially influence the cost of collusion among airlines (H2b).

Table 8: Market structure and deregulation (H2)

\begin{tabular}{|c|c|c|c|c|c|}
\hline & \multicolumn{5}{|c|}{$d_{r t}$} \\
\hline & (1) & $(2)$ & (3) & (4) & $(5)$ \\
\hline$J_{r t}$ & & $\begin{array}{c}-0.01^{* *} \\
(0.005)\end{array}$ & $\begin{array}{l}-0.009^{*} \\
(0.005)\end{array}$ & $\begin{array}{c}-0.01^{* * *} \\
(0.003)\end{array}$ & $\begin{array}{c}-0.012^{* * *} \\
(0.004)\end{array}$ \\
\hline$H H I_{r t}$ & $\begin{array}{c}0.043^{* *} \\
(0.018)\end{array}$ & $\begin{array}{c}0.005 \\
(0.024)\end{array}$ & & & \\
\hline SameGroup & & & $\begin{array}{l}-0.003 \\
(0.08)\end{array}$ & & \\
\hline$\%(S O E)$ & & & & $\begin{array}{c}0.016 \\
(0.018)\end{array}$ & \\
\hline$\#(S O E)$ & & & & & $\begin{array}{c}0.005 \\
(0.009)\end{array}$ \\
\hline Other Controls & YES & YES & YES & YES & YES \\
\hline$\delta_{t}, \alpha_{r}$ & YES & YES & YES & YES & YES \\
\hline$R^{2}$ & 0.560 & 0.561 & 0.561 & 0.561 & 0.561 \\
\hline Obs. & & & 4503 & & \\
\hline
\end{tabular}

Table 8 presents the estimation results exploring the impact of collusion cost. The most commonly used measure for market structure, the Hirschman-Hirfendahl Index, $H H I_{r t}$, captures market concentration, and thus a higher HHI implies greater concentration of market shares and greater ease to collude. But as this measure is highly correlated with the number of airlines operating in 
the market, the effect disappears once the number of airlines is added back into the estimation in column (2) in table 8, although the HHI measure has a positive and significant effect on airfare cap removal in column (1).

Three other variables are better measures for collusion cost. The first is SameGroup, which is the binary variable indicating whether all airlines operating in the air route belong to the same airline group ${ }^{17}$. And we argue that it is easier for the airlines to collude for capture purposes if they belong to the same airline group, due to personnel and financial connections that facilitate communication. The second measure is the total market share occupied by centrally administered stated-owned airline groups in the air route $\%(S O E)$. As all central SOEs are administered by the SASAC (State-owned Assets Supervision and Administration Commission), it is reasonable to assume implicit collusion becomes easier among central SOE airlines operating in the same route. Similarly, we use the number of centrally administered SOEs, \# $S O E)$ as the third measure. For all these measures, a larger value corresponds to lower collusion cost. Thus, we predict significantly positive effects on airfare cap removal, if the regulatory capture theory is applicable. The more telling pattern is exhibited in columns (3)-(5) in table 8, where none of the estimates for the collusion cost measures are significant, whereas the effect of the number of airlines operating in the air route remains negative and significant, with the magnitude largely stable.

In sum, the estimates suggest no significant relationship between airfare cap removal and market structure features that may influence collusion cost, thus providing no supporting evidence for potential collusion among airlines to capture the regulator.

\subsubsection{Testing Hypothesis H3: Impact on Exit/Entry}

Next, we examine the impact of airfare deregulation on airline exit/entry (H3), with the following specification:

$$
E_{r t+1}=\psi d_{r t}+\beta J_{r t}+\delta_{t}+\alpha_{r}+\epsilon_{r t},
$$

\footnotetext{
${ }^{17}$ The following rule is used to determine whether two airlines belong to the same airline group: If two airlines have cross shareholding relationship, then they belong to the same airline group.

${ }^{18}$ The centrally administered stated-owned airline groups include the three airlines that are majority owned and administered by the Chinese central government: Air China, China Eastern Airlines, and China Southern Airlines.
} 
where $E_{r t+1}$ indicates the airlines' exit or entry decision in the year after the airfare cap removal, with Allexit $_{r+1}$ denoting the next year's exit decision of all airlines in a route and entry $y_{r t+1}$ denoting the next year's entry decision of an additional airline.

Table 9: Deregulation and exit/entry (H3)

\begin{tabular}{cccccc}
\hline \multicolumn{4}{c}{ Allexit $_{r t+1}$} & \multicolumn{3}{c}{ entry $_{r t+1}$} & $J_{r t}$ \\
& $(1)$ & $(2)$ & $(3)$ & $(4)$ & $(5)$ \\
\hline \multirow{2}{*}{$d_{r t}$} & $-0.074^{* * *}$ & $-0.075^{* * *}$ & -0.313 & $-0.290^{* *}$ & -0.165 \\
& $(0.008)$ & $(0.008)$ & $(0.236)$ & $(0.129)$ & $(0.215)$ \\
$J_{r t}$ & & $-0.008^{*}$ & & $-0.252^{* * *}$ & \\
& & $(0.012)$ & & $(0.014)$ & \\
\hline Other Controls & YES & YES & YES & YES & YES \\
$\delta_{t}, \alpha_{r}$ & YES & YES & YES & YES & YES \\
\hline$R^{2}$ & 0.072 & 0.074 & 0.005 & 0.234 & 0.162 \\
Obs. & \multicolumn{5}{c}{3085} \\
\hline
\end{tabular}

Notes: Other control variables include $H S R_{r t}$, dis600* year 14 , and dis $800 *$ year 16 .

$* *, * *$ and $*$ denotes $1 \%, 5 \%$ and $10 \%$ significance level. All errors are clustered at route level.

Table 9 presents the estimation results when studying the patterns of airline entry/exit. The results show a significant and negative relationship between airfare cap elimination in the current year $d_{r t}$ and the next year's exit decision by all airlines, Allexit $t_{r+1}$. It implies that the airfare cap elimination does prevent all airlines' exiting from the market, which is consistent with the mechanism in the public interest theory. Such an effect does not vary after controlling for the number of airlines $J_{r t}$ and various market structure variables.

We might expect the markets to become more profitable after price caps are removed, thus exit less likely regardless of whether deregulation took place due to public interest considerations or regulatory capture. But the public interest theory will further predict that the increased profitability, through removing airfare caps, is only enough to prevent exit, yet not enough to attract new entry, because the underlying assumption of the theory is that the market in question is unprofitable for at least some incumbents and price cap should be removed to raise profitability just for them not to exit. In contrast, the regulatory capture theory will predict that entry becomes more likely after deregulation, as the market becomes more profitable. The estimates in columns (3) and (4) suggest no significant relationship or negative relationship between airfare deregulation and airline entry, while columns (5) show that the total number of airlines does not change significantly after deregulation. This is, again, consistent with the prediction of the public interest theory, in which the deregulation decision is to prevent airline from exiting rather than making the market lucrative 
to attract new entrants.

In summary, we examine the three sets of hypotheses regarding how market demand, market structure and entry/exit relate to airfare cap removals to distinguish the two competing theories. We find that airfare caps are not more likely to be removed in routes with higher market demand and that market structure variables related to collusion costs have no effect on airfare deregulation decisions. In addition, the airfare cap removal does prevent all airlines from exiting but does not lead to more entry. These findings thus provide consistent support for the predictions of the public interest theory, where the regulator pursues the goal of keeping more markets served, which can be viewed as a form of universal service obligations.

\section{Robustness Tests}

We present results from additional robustness tests in this section, which address the potential issue of sample selection as well as potential differences across waves of deregulation.

\subsection{Addressing Potential Sample Selection}

As both our airfare data and the CAAC flight time-table data fail to cover the least popular air routes, one may be concerned that our sample is biased toward more "popular" routes that connect cities with higher GDP and larger population, compared with all routes. Table 10 compares the routes in our sample and all routes. Indeed, the routes in our sample correspond to cities with higher GDP, larger population, and higher likelihood of having direct connection by high-speed rails (HSR). In this section, we present evidence to show that the potential sample bias further strengthens our findings.

Table 10: Sample routes versus all routes

\begin{tabular}{ccccccc}
\hline & \multicolumn{3}{c}{ Sample Routes } & \multicolumn{3}{c}{ All Routes } \\
& mean & s.d. & obs. & mean & s.d. & obs. \\
\hline HSR & 0.137 & 0.343 & 4503 & 0.105 & 0.307 & 6984 \\
distance & 1281 & 628.4 & 4503 & 1234 & 641.2 & 6984 \\
$\ln$ GDP & 17.18 & 0.720 & 3349 & 16.87 & 0.903 & 5054 \\
$\ln$ gdp & 11.57 & 0.353 & 3349 & 11.32 & 0.612 & 5054 \\
$\ln$ pop & 5.618 & 0.565 & 3349 & 5.544 & 0.574 & 5054 \\
\hline Data Sources: City Statistical Yearbooks of China (2013-2016).
\end{tabular}

For the airfare data, one potential suspicion is that the negative relation between airfare and the 
number of airlines that we have observed earlier may not apply for less popular routes. To address this concern, we conduct the following estimation for different subsamples, where the pattern is studied first for the whole sample and then for subsamples consisting of air routes with different numbers of airlines operating in them.

Table 11: Airfare versus number of airlines (using different samples)

\begin{tabular}{ccccc}
\hline & \multicolumn{4}{c}{$\ln p_{\text {rjdh }}$} \\
& $(1)$ & $(2)$ & $(3)$ & $(4)$ \\
\hline \multirow{2}{*}{$J_{r d}$} & $-0.060^{* * *}$ & $-0.078^{* * *}$ & $-0.064^{* * *}$ & $-0.036^{* * *}$ \\
& $(0.009)$ & $(0.010)$ & $(0.007)$ & $(0.011)$ \\
3-day & -0.01 & -0.009 & -0.004 & -0.002 \\
& $(0.008)$ & $(0.009)$ & $(0.009)$ & $(0.009)$ \\
14-day & 0.012 & 0.005 & 0.017 & 0.018 \\
& $(0.015)$ & $(0.015)$ & $(0.016)$ & $(0.017)$ \\
21-day & $0.053^{* * *}$ & $0.055^{* * *}$ & $0.057^{* * *}$ & $0.061^{* * *}$ \\
& $(0.008)$ & $(0.007)$ & $(0.008)$ & $(0.008)$ \\
\hline fixed effect & $\gamma_{j r}, \mu_{d}, \delta_{h}$ & $\gamma_{j r}, \mu_{d}, \delta_{h}$ & $\gamma_{j r}, \mu_{d}, \delta_{h}$ & $\gamma_{j r}, \mu_{d}, \delta_{h}$ \\
\hline$R^{2}$ & 0.574 & 0.609 & 0.579 & 0.596 \\
Obs. & 2731820 & 1739934 & 2439859 & 2403159
\end{tabular}

Notes: Column (1) is the whole sample; Column (2) restricts the sample with the number of airlines from 1 to 4 ; Column (3) restricts the sample with the number of airlines from 2 to 5; Column (4) restricts the sample with the number of airlines no less than 3.

$* * *,{ }^{* *}$ and $*$ denotes $1 \%, 5 \%$ and $10 \%$ significance level. All errors are clustered at route level.

As shown in table 11 above, the negative correlation between the number of airlines and airfare level is stronger for routes with fewer airlines operating in them. Because less popular routes tend to have fewer airlines in operation, we view these results as evidence that the exclusion of the less popular air routes from our sample may lead to more significant negative relationship between the number of airlines and airfare level, thus further strengthening our findings.

Similarly, to address the potential concern of sample bias in the CAAC flight time-table data, we conduct the following analysis. In particular, the routes are divided into two subsamples based on the level of GDP. The sample in column (1) includes air routes that connect city pairs with GDP below the median level of the whole sample, while that in column (2) includes the other air routes above the median level.

As shown in the estimation results in table 12, the number of airlines in the air route is negatively correlated with the probability of airfare cap removal in both subsamples, with similar significance and magnitude of the coefficient estimate. The slightly larger and more significant correlation estimated from the subsample of air routes with lower market size and profit potential demonstrates 
Table 12: Deregulation versus number of airlines (using different samples)

\begin{tabular}{ccc}
\hline & \multicolumn{2}{c}{$d_{r t}$} \\
& $(1)$ & $(2)$ \\
\hline$J_{r t}$ & $\left(0.012^{*}\right.$ & -0.009 \\
& $(0.007)$ & $(0.006)$ \\
& $0.172^{* * *}$ & $0.059^{* *}$ \\
& $(0.064)$ & $(0.023)$ \\
dis600 * year 14 & $0.317^{* * *}$ & $0.203^{* * *}$ \\
& $(0.072)$ & $(0.064)$ \\
dis600 * year 14 & $0.618^{* * *}$ & $0.814^{* * *}$ \\
& $(0.055)$ & $(0.040)$ \\
\hline Time/Route Fixed Effect & Yes & Yes \\
\hline$R^{2}$ & 0.482 & 0.632 \\
Obs. & 1664 & 1685 \\
\hline Notes: ${ }^{* * *},{ }^{* *}$ and ${ }^{*}$ denotes 1\%, $5 \%$ and $10 \%$ significance level; \\
All errors are clustered at route level.
\end{tabular}

the importance of public interest in the deregulation decision-making process, as the universal service obligation is more relevant in economically backward regions. It also helps ease the concern regarding sample selection bias, as the pattern suggests that the less popular routes exhibit stronger correlations between the number of airlines and deregulation probability, which implies a potential underestimation of effects and thus further strengthens our conclusion in support of the public interest theory.

\subsection{Comparing Deregulation across Waves}

Our sample on airfare deregulation covers three waves of airfare cap removals in year 2013, 2014 and 2016. Table 13 provides the summary statistics of various market characteristics for the different air routes that went through various waves of airfare cap removals. As shown in the table, the four waves of airfare cap removals have all involved shorter air routes that had direct connection to HSR, which was consistent with one of the guiding principles stated in the various documents (see footnote 5). But the likelihood of deregulation had no persistent correlation with other characteristics of the air routes, such as the size of economy, the size of population, or the level of development in the connecting cities.

One may wonder whether the regulator has given consistent weight to public interest, including the universal service obligation, over the years. To address this issue, we conduct the following estimations where the interaction terms between different wave indicator and the number of airlines 
Table 13: Deregulated routes versus non-deregulated routes across waves

\begin{tabular}{cccccccc}
\hline & & \multicolumn{3}{c}{ Deregulated Routes } & \multicolumn{3}{c}{ Non-deregulated Routes } \\
& & mean & s.d. & obs. & mean & s.d. & obs. \\
\hline & $H S R$ & 0 & 0 & 94 & 0 & 0 & 923 \\
& distance & 381.6 & 199.0 & 94 & 1211 & 628.1 & 923 \\
first wave (2004) & $\ln G D P$ & 15.29 & 0.967 & 44 & 15.72 & 0.704 & 724 \\
& $\ln g d p$ & 9.975 & 0.510 & 44 & 10.21 & 0.398 & 724 \\
& $\ln p o p$ & 5.312 & 0.639 & 44 & 5.515 & 0.551 & 724 \\
\hline & $H S R$ & 0.935 & 0.250 & 31 & 0.0720 & 0.259 & 1694 \\
& distance & 719.0 & 230.3 & 31 & 1112 & 553.2 & 1694 \\
second wave (2013) & $\ln G D P$ & 18.13 & 0.557 & 29 & 17.00 & 0.747 & 1274 \\
& $\ln g d p$ & 11.81 & 0.345 & 29 & 11.47 & 0.368 & 1274 \\
& $\ln p o p$ & 6.319 & 0.400 & 29 & 5.534 & 0.563 & 1274 \\
\hline & $H S R$ & 0.168 & 0.376 & 101 & 0.104 & 0.305 & 2073 \\
& $\operatorname{distance}$ & 399.8 & 98.67 & 101 & 1331 & 661.6 & 2073 \\
& $\ln G D P$ & 16.84 & 0.676 & 72 & 17.05 & 0.739 & 1457 \\
& $\ln g d p$ & 11.48 & 0.404 & 72 & 11.53 & 0.359 & 1457 \\
& $\ln p o p$ & 5.363 & 0.473 & 72 & 5.519 & 0.571 & 1457 \\
\hline & $H S R$ & 0.365 & 0.482 & 375 & 0.126 & 0.332 & 1693 \\
& $\operatorname{distance}$ & 605.1 & 151.0 & 375 & 1494 & 601.6 & 1693 \\
fhird wave (2014) & $\ln G D P$ & 17.21 & 0.795 & 293 & 17.16 & 0.768 & 1161 \\
& $\ln g d p$ & 11.61 & 0.402 & 293 & 11.56 & 0.388 & 1161 \\
& $\ln p o p$ & 5.598 & 0.574 & 293 & 5.594 & 0.593 & 1161 \\
\hline
\end{tabular}

Data Sources: CAAC flight time-tables, deregulation announcements, and City Yearbooks of China (2013-2016).

are included. As shown in table 14, we find that although there have been some differences over time (with a stronger correlation in 2014), the correlation between the number of airlines and the probability of airfare cap removal has remained negative and significant throughout the years. Such robust correlation over different waves, again, provides consistent support for the public interest theory.

\section{Conclusion}

The existing literature on regulation has two common features: More studies have been conducted in the context of developed countries rather than developing economies, and the consequences of regulation or deregulation have been explored more thoroughly than the causes, especially in the case of deregulation. The recent history of China's economic reforms has provided a good opportunity to expand the scope of regulation research, by allowing exploration into several issues regarding regulation and deregulation in a large developing country. In particular, the gradualist 
Table 14: Deregulation versus number of airlines (across waves)

$$
\begin{array}{cc}
\hline & d_{r t} \\
\cline { 2 - 3 } J_{r t} & -0.012^{* * *} \\
& (0.004) \\
J_{r t} * \text { year14 } & -0.010^{* * *} \\
& (0.003) \\
J_{r t} * \text { year } 16 & 0.004 \\
& (0.004) \\
H S R_{r t} & 0.085^{* * *} \\
& (0.019) \\
\text { dis600* year14 } & 0.280^{* * *} \\
& (0.043) \\
\text { dis800* year16 } & 0.740^{* * *} \\
& (0.030) \\
\hline \delta_{t}, \alpha_{r} & \text { YES } \\
\hline R^{2} & 0.564 \\
\text { Obs. } & 4503 \\
\hline \text { and }{ }^{*} \text { denotes } 1 \%, 5 \% \text { and } 10 \% \text { significance level. } \\
\text { All errors are clustered at route level. }
\end{array}
$$

approach in reforming China's airline industry has led to regional variations in the timing of airfare cap removal, which allows us to explore the causes of deregulation.

Motivated by the two seemingly contradictory patterns, where the airfare cap eliminations are more likely to be implemented in routes with fewer airlines where airfares tend to be higher and thus the price caps more binding, the current study proposes a theoretical model in which both the public interest theory and the regulatory capture theory are taken into account. While the public interest theory highlights the mechanism of potential airline exit, the regulatory capture theory emphasizes the potential collusion among airlines.

Using newly available data, we find empirical evidence more in support of the public interest theory, rather than the regulatory capture theory. In particular, Chinese regulators of the airline industry seem to pursue public interest when lifting airfare caps, and their concern with market exit and the consequent failure to serve certain markets is the main reason for removing airfare caps in routes served by fewer airlines.

In contrast to studies that investigate consequences of deregulation in the airline industry, we explore the motivation for airline deregulation. In particular, the study supplements the main finding in the literature that regulation is more likely motivated by regulatory capture whereas deregulation is driven by the pursuit of the public interest. We also contribute to the literature by 
emphasizing the implication of universal service obligations for studying deregulation in developing countries.

Additional research is needed to explore more details in the process of deregulation in China's airline industry, including how the timing of airfare cap removals has been chosen, as well as how market entry deregulation is coordinated with price deregulation. More generally, while our findings paint the image of publicly minded regulators in China's airline industry, it would be interesting to explore whether the positive image is also an accurate depiction of regulators in other sectors, especially those with longer histories and thus more vested interest groups. And if different patterns emerge, what factors could account for the differences. Relatedly, what lessons can be learned regarding the most appropriate approach to deregulation, based on such findings. Given the size and complexity of the Chinese economy, such future endeavors could potentially help us gain many insights in the process of regulatory reforms in both transition economies and the developing world. 


\section{Appendices}

\subsection{Appendix I: Proofs}

\subsubsection{Proof for Proposition 1}

Proposition 1: Under the condition of $1<(p-c)<\frac{J}{J-1}$ for all $p$, the competitive airfare $p^{*}$ decreases with the number of airlines $J$.

Proof: Each airline competitively chooses $p$, given other airlines' competitive airfare at $p^{*}$. The competitive airfare $p^{*}$ determined by the following:

$$
\ln \frac{p-c-1}{1-(J-1)(p-c-1)}=\theta-p
$$

where the LHS is increasing in $J$ for all $p$, whereas the RHS is invariant to $J$. The intersection determines the competitive price $p^{*}$, which can be illustrated in the following graph:

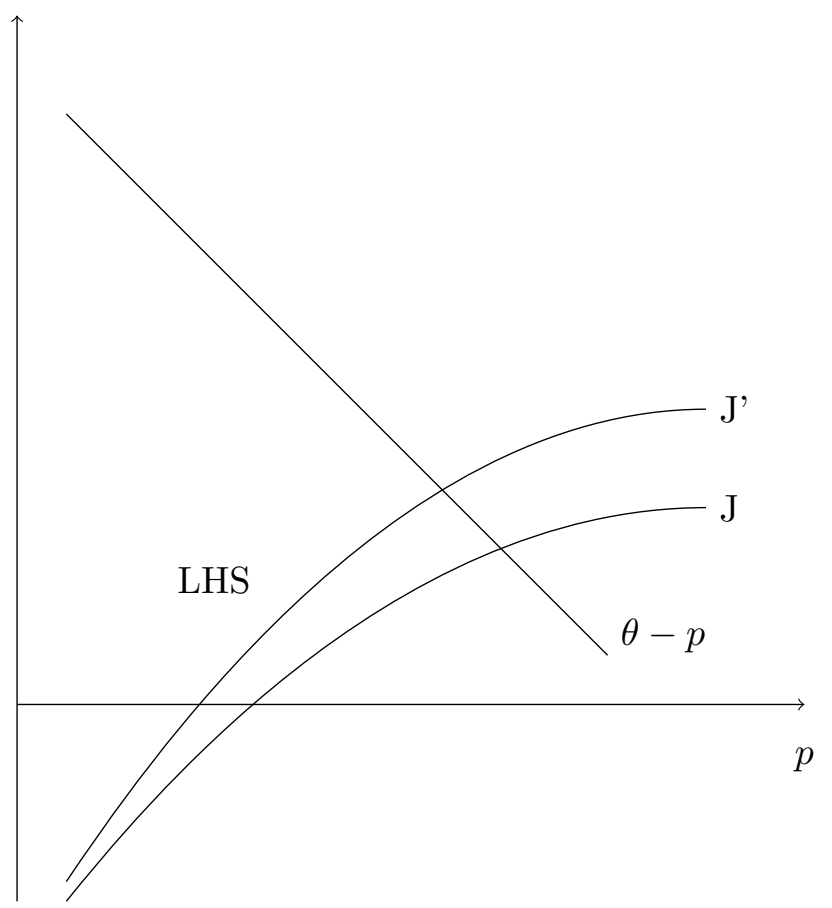

Figure 5: Graphic illustration for proposition $1\left(J^{\prime}>J\right)$ 


\subsubsection{Proofs for Propositions 2 and 3}

We first introduce Lemmas 1 and 2 to help develop Propositions 2 and 3.

Lemma 1: Under the condition that $\frac{\partial p^{*}}{\partial J}<0$ is sufficiently small, we have the following:

$$
\frac{\partial C S(\bar{p}, J)}{\partial J}-\frac{\partial C S\left(p^{*}, J\right)}{\partial J}>0
$$

Proof: Without the airfare cap, an increase in the number of airlines, $J$, have two effects: the price effect $\left(\frac{\partial p^{*}}{\partial J}\right)$ and the variety effect $\left(\frac{\operatorname{Jexp}\left(\theta-p^{*}\right)}{1+\operatorname{Jexp}\left(\theta-p^{*}\right)}\right)$, both of which increase the consumer surplus. However, only the variety effect exists $\left(\frac{\operatorname{Jexp}(\theta-\bar{p})}{1+\operatorname{Jexp}(\theta-\bar{p})}\right)$ with the presence of the airfare cap, because $\bar{p}$ does not vary with $J$. Since $p^{*}>\bar{p}$, we have

$$
\frac{\exp (\theta-\bar{p})}{1+J \exp (\theta-\bar{p})}>\frac{\exp \left(\theta-p^{*}\right)}{1+J \exp \left(\theta-p^{*}\right)}
$$

Under the condition that $\frac{\partial p^{*}}{\partial J}<0$ is sufficiently small, we still have

$$
\frac{\exp (\theta-\bar{p})}{1+J \exp (\theta-\bar{p})}>\frac{\exp \left(\theta-p^{*}\right)}{1+J \exp \left(\theta-p^{*}\right)}\left(1-J \frac{\partial p^{*}}{\partial J}\right)
$$

It alternatively suggests $\frac{\partial C S(\bar{p}, J)}{\partial J}-\frac{\partial C S\left(p^{*}, J\right)}{\partial J}>0$.

In other words, the marginal benefit from having an additional airline on consumer surplus lies in two aspects: a decrease in price $p^{*}$ and an increase in variety. As the binding airfare cap is invariant to the number of airlines, only the variety effect exists when the airfare cap is maintained. Lemma 1 states the wedge between consumer surplus with airfare cap and that without airfare cap increases as the number of airlines increases, if the price effect is relatively small.

Lemma 2: If the extra consumer surplus loss $\Delta>0$ is sufficiently large, then we have when $m>1$ :

$$
C S(\bar{p}, m)-C S(\bar{p}, m-1)=o(C S(\bar{p}, 1))
$$

Proof: When $m=1, C S(\bar{p}, 1)-C S(\bar{p}, 0)=\ln [1+\exp (\theta-\bar{p})]+\Delta$ because $C S(\bar{p}, 0)=0$. When $m>1, C S(\bar{p}, m)-C S(\bar{p}, m-1)=\ln \frac{[1+\operatorname{mexp}(\theta-\bar{p})]}{[1+(m-1) \exp (\theta-\bar{p})]}$. Because $\theta>\bar{p}$, we have $C S(\bar{p}, m)-$ 
$C S(\bar{p}, m-1) \approx \ln \frac{m}{m-1}$. Again, since $\Delta$ is sufficiently large,

$$
\frac{C S(\bar{p}, m)-C S(\bar{p}, m-1)}{C S(\bar{p}, 1)-C S(\bar{p}, 0)}=\frac{\ln \frac{m}{m-1}}{\ln [1+\exp (\theta-\bar{p})]+\Delta}=o(1)
$$

Given $C S(\bar{p}, 0)=0$, the above is equivalent to: $C S(\bar{p}, m)-C S(\bar{p}, m-1)=o(C S(\bar{p}, 1))$.

The Lemma 2 illustrates that the main loss of consumer surplus comes from all airlines' exiting that leaves the market un-served, mainly due to the concavity of the consumer surplus function and, in particular, extra surplus loss $\Delta$.

Proposition 2: As long as $k$ is not too large, the regulator in the public interest theory is more likely to eliminate the airfare cap in markets with fewer airlines and smaller market size.

Proof: The regulator compares the consumer surplus difference in the cases with and without airfare cap:

$$
\max \left\{\bar{W}^{P I}, W^{P I}\right\}
$$

According to Lemma 2, $C S(\bar{p}, m)-C S(\bar{p}, m-1)=o(C S(\bar{p}, 1))$ for $m>1$. The consumer surplus with the airfare cap can be expressed as:

$$
\bar{W}^{P I}=\left(1-k^{J}\right) C S(\bar{p}, J)-k^{J} \Delta+o(C S(\bar{p}, 1))+\bar{\zeta}
$$

Thus, we have

$$
\frac{\partial \operatorname{Pr}\left(\bar{W}^{P I}-W^{P I}\right)}{\partial J}=\phi(.) *\left[-k^{J} \ln k(C S(\bar{p}, J)+\Delta)+\left(1-k^{J}\right) \frac{\partial C S(\bar{p}, J)}{\partial J}-\frac{\partial C S\left(p^{*}, J\right)}{\partial J}\right],
$$

where $\phi$ denotes the density of $(\zeta-\bar{\zeta})$. According to Lemma 1, we have $\frac{\partial C S(\bar{p}, J)}{\partial J}>\frac{\partial C S\left(p^{*}, J\right)}{\partial J}$.

When $k \rightarrow 1,-k^{J} \ln k(C S(\bar{p}, J)+\Delta) \approx 0$ and $\left(1-k^{J}\right) \frac{\partial C S(\bar{p}, J)}{\partial J} \approx 0, \frac{\partial \operatorname{Pr}\left(\bar{W}^{P I}-W^{P I}\right)}{\partial J}=$ $-\frac{\partial C S\left(p^{*}, J\right)}{\partial J}<0$. When $k \rightarrow 0,-k^{J} \ln k(C S(\bar{p}, J)+\Delta) \approx 0$ and $\left(1-k^{J}\right) \frac{\partial C S(\bar{p}, J)}{\partial J}-\frac{\partial C S\left(p^{*}, J\right)}{\partial J} \approx$ $\frac{\partial C S(\bar{p}, J)}{\partial J}-\frac{\partial C S\left(p^{*}, J\right)}{\partial J}>0$. Consequently, as long as $k$ is not too large, we have:

$$
\frac{\partial \operatorname{Pr}\left(\bar{W}^{P I}-W^{P I}\right)}{\partial J}>0
$$

Since $\bar{p}<p^{*}$, for large $J$, the probability of all airline exiting becomes trivial so that the effect 
$\ln [1+\operatorname{Jexp}(\theta-\bar{p})]>\ln \left[1+\operatorname{Jexp}\left(\theta-p^{*}\right)\right]$ dominates. Thus, as long as $k$ is not too large, we have

$$
\frac{\partial \operatorname{Pr}\left(\bar{W}^{P I}-W^{P I}\right)}{\partial N}=\left(1-k^{J}\right) \ln [1+J \exp (\theta-\bar{p})]-\ln \left[1+J \exp \left(\theta-p^{*}\right)\right]>0
$$

Consequently, the regulator tends to remove airfare caps in routes with fewer airlines and smaller market size.

Proposition 3: Under the condition that $\lambda$ is sufficiently large, the regulator in the regulatory capture theory is more likely to eliminate the airfare cap in routes with fewer airlines, less difficulty in collusion and larger market size.

Proof:

$$
\frac{\partial \operatorname{Pr}\left(\bar{W}^{R C}-W^{R C}\right)}{\partial J}=s(.) *\left[\frac{\partial\left(C S(\bar{p}, J)-C S\left(p^{*}, J\right)\right)}{\partial J}-\frac{\partial \lambda}{\partial J}\right]
$$

where $s($.$) denotes the density of (\eta-\bar{\eta})$. The first term $\frac{\partial\left(C S(\bar{p}, J)-C S\left(p^{*}, J\right)\right)}{\partial J}>0$, according to Lemma 1. Because $\frac{\partial \lambda}{\partial J}<0$, we have

$$
\frac{\partial \operatorname{Pr}\left(\bar{W}^{R C}-W^{R C}\right)}{\partial J}=\frac{\partial\left(C S(\bar{p}, J)-C S\left(p^{*}, J\right)\right)}{\partial J}-\frac{\partial \lambda}{\partial J}>0
$$

This implies that the regulator is likely to remove airfare caps in routes with fewer airlines. Meanwhile, since $\frac{\partial \lambda}{\partial \chi}>0$, we would also expect

$$
\frac{\partial \operatorname{Pr}\left(\bar{W}^{R C}-W^{R C}\right)}{\partial \chi}=-s(.) * \frac{\partial \lambda(J, \chi)}{\partial \chi}<0
$$

It also implies that the regulator is less likely to remove the airfare cap in a route where collusion is more difficult (low $\chi$ ). Without regulatory capture, namely $\frac{\partial \lambda}{\partial J}=0$ and $\frac{\partial \lambda}{\partial \chi}=0$, we would have $\frac{\partial \operatorname{Pr}\left(\bar{W}^{R C}-W^{R C}\right)}{\partial J}>0$ and $\frac{\partial \operatorname{Pr}\left(\bar{W}^{R C}-W^{R C}\right)}{\partial \chi}=0$, which, combined together, suggest: (1) the regulator should remove the airfare cap in routes with fewer airlines; and, (2) the market structure variables do not affect the removal decision.

Moreover, under the condition that the capture benefit $\lambda$ is sufficiently large such that

$$
\frac{\partial \operatorname{Pr}\left(\bar{W}^{R C}-W^{R C}\right)}{\partial N}=s(.) *\left[\ln (1+J(\theta-\bar{p}))-\ln \left(1+J\left(\theta-p^{*}\right)\right)-\lambda\right]<0,
$$


the regulator is more likely to remove airfare cap in routes with large market size. 


\subsection{Appendix II: Robustness Tests on Number of Airlines versus Airfares}

Instead of pooling tickets together, we conduct separate analysis using subsamples categorized by days of advance purchase. Similar results are obtained.

Table 15: Number of airlines versus airfare (subsamples by days of advance purchase)

\begin{tabular}{ccccc}
\hline \multicolumn{5}{c}{$\ln p_{r j d h}$} \\
& 3-day & 7-day & 14-day & 21-day \\
\hline \multirow{2}{*}{$J_{r d}$} & $-0.028^{* * *}$ & $-0.022^{* * *}$ & $-0.024^{* * *}$ & $-0.017^{* * *}$ \\
& $(0.007)$ & $(0.007)$ & $(0.007)$ & $(0.007)$ \\
\hline$\gamma_{j r}, \mu_{d}, \delta_{h}$ & YES & YES & YES & YES \\
\hline$R^{2}$ & 0.781 & 0.793 & 0.799 & 0.763 \\
Obs. & 666288 & 693016 & 712522 & 702266 \\
\hline Notes: ${ }^{* * *},{ }^{* *}$ and ${ }^{*}$ denote $1 \%, 5 \%$ and 10\% significance level. & All errors are clustered at route level.
\end{tabular}

Table 16: Number of airlines versus airfare (airfare cap indicator as dependent variable)

\begin{tabular}{ccccc}
\hline \multicolumn{5}{c}{$\mathbf{1}$ (airfare cap) } \\
& 3-day & 7-day & 14-day & 21-day \\
\hline \multirow{2}{*}{$J_{r d}$} & $-0.029^{* * *}$ & $-0.035^{* * *}$ & $-0.034^{* * *}$ & $-0.029^{* * *}$ \\
& $(0.007)$ & $(0.007)$ & $(0.008)$ & $(0.007)$ \\
\hline$\gamma_{j r}, \mu_{d}, \delta_{h}$ & YES & YES & YES & YES \\
\hline$R^{2}$ & 0.752 & 0.744 & 0.726 & 0.590 \\
Obs. & 666288 & 693016 & 712522 & 702266 \\
\hline Notes: ${ }^{* * *},{ }^{* *}$ and ${ }^{*}$ denote $1 \%, 5 \%$ and 10\% significance level. & All errors are clustered at route level.
\end{tabular}




\subsection{Appendix III: Robustness Tests on Number of Airlines versus Deregulation}

Instead of using the number of airlines, we use a set of dummies to indicate each particular number of airlines in a route, with routes operated by at least four airlines serving as the benchmark. The estimates provide robust evidence on the previous pattern that airfare caps are more likely to be removed in routes with fewer airlines. Column (1) and (2) adopt different definitions in terms of number of airlines, where an airline is defined as the one with market share above $5 \%$ and $\% 10$ in the route, respectively.

Table 17: Number of airlines versus deregulation (categorical indicators for number of airlines)

\begin{tabular}{ccc}
\hline & \multicolumn{2}{c}{$d_{r t}$} \\
& $(1)$ & $(2)$ \\
\hline$J_{r t}=1$ & $0.049^{* * *}$ & $0.044^{* * *}$ \\
& $(0.016)$ & $(0.016)$ \\
$J_{r t}=2$ & $0.044^{* * *}$ & $0.042^{* * *}$ \\
& $(0.016)$ & $(0.016)$ \\
$J_{r t}=3$ & $0.024^{*}$ & $0.020^{*}$ \\
& $(0.013)$ & $(0.012)$ \\
$H S R_{r t}$ & $0.085^{* * *}$ & $0.085^{* * *}$ \\
& $(0.018)$ & $(0.019)$ \\
dis600* year14 & $0.287^{* * *}$ & $0.287^{* * *}$ \\
& $(0.043)$ & $(0.044)$ \\
dis800* year16 & $0.740^{* * *}$ & $0.741^{* * *}$ \\
& $(0.030)$ & $(0.030)$ \\
\hline$\delta_{t}, \alpha_{r}$ & YES & YES \\
\hline$R^{2}$ & 0.561 & 0.561 \\
Obs. & 4503 & 4503 \\
\hline Notes: ***,** and ${ }^{*}$ denotes $1 \%, 5 \%$ and $10 \%$ significance level. \\
All errors are clustered at route level.
\end{tabular}




\section{References}

[1] Becker, G. S. 1983. A Theory of Competition Among Pressure Groups for Political Influence, Quarterly Journal of Economics 98 (3): 371-400.

[2] Borenstein, S. 1992. The Evolution of US Airline Competition. Journal of Economic Perspectives 6 (2): 45-73.

[3] Borenstein, S, and N. Rose. 1994. Competition and Price Dispersion in the US Airline Industry. Journal of Political Economy 102 (4): 653-83.

[4] Borenstein, S, and N. Rose. 2013. How Airline Markets Work...or Do They? Regulatory Reform in the Airline Industry, Chapter 2 in Economic Regulation and Its Reform: What Have We Learned?, 63-135.

[5] Brueckner, J., and P. Spiller. 1994. Economies of Traffic Density in the Deregulated Airline Industry. Journal of Law and Economics 37 (2): 379-415.

[6] Danzon P. M., Wang Y. R.,and Wang L. 2005. The Impact of Price Regulation on the Launch Delay of New Drugs-Evidence from Twenty-five Major Markets in the 1990s. Health Economics 14 (3): 269-292.

[7] Davey A. 2010. Deregulation of Wholesale Petrol Prices: What Happened to Capital City Petrol Prices?. Australian Journal of Agricultural $\& 3$ Resource Economics 54 (1): 81-98.

[8] Djankov, S., R., La Porta, F. Lopez-De-Silanes, and A. Shleifer. 2002. The Regulation of Entry. Quarterly Journal of Economics 117 (1): 1-37.

[9] Flores S. M.,and Shepherd J. C. 2014. Pricing Out the Disadvantaged? The Effect of Tuition Deregulation in Texas Public Four-Year Institutions. Annals of the American Academy of Political \& Social Science 655 (1): 99-122.

[10] Gaggero, A., Piga, C. 2010. Airline competition in the British Isles. Transportation Research Part E 46: 270-279.

[11] Gerardi, Kristopher, and Adam Hale Shapiro. 2009. Does Competition Reduce Price Dispersion? New Evidence from the Airline Industry. Journal of Political Economy 117 (1): 1-37.

[12] Gillen, D., and Hazledine, T., 2006. The new price discrimination and pricing in airline: implications for competition and antitrust, Paper for XIV Pan-American Conference of Traffic E Transportation Engineering, September 20-23: 1-25.

[13] Kang L., and Zarnikau J. 2014. Did the Expiration of Retail Price Caps Affect Prices in the Restructured Texas Electricity Market? Energy Policy 37 (5): 1713-1717.

[14] Goolsbee, A., and C. Syverson. 2008. How Do Incumbents Respond to the Threat of Entry? Evidence from Major Airlines. Quarterly Journal of Economics, 123(4): 1611-1633. 
[15] Levine, M. E. 1987. Airline Competition in Deregulated Markets: Theory, Firm Strategy and Public Policy. Yale Journal on Regulation 4 (Spring): 393-494.

[16] MacAvoy, P., and R. Schmalensee. The Causes and Effects of Deregulation, England: Edward Elgar, 2014, 123 (4): 1611-33.

[17] Peltzman S. 1976. Toward a More General Theory of Regulation. Journal of Law and Economics 19 (2): 211-240.

[18] Resende, M., and Facanha, L. O. 2005. Price-cap regulation and service-quality in telecommunications: an empirical study. Information Economics and Policy 17(1): 1-12.

[19] Roos, N.D., Mills, G., Whelan, S., 2010. Pricing dynamics in the Australian airline market. Economic Record 86: 545-562.

[20] Rovizzi, L., and Thompson, D. 1992. The regulation of product quality in the public utilities and the citizen's charter. Fiscal Studies 13(3): 74-95.

[21] Stigler, G. J. 1971. The theory of economic regulation. The Bell journal of economics 2(1):321.

[22] Traub, L. N., and Jayne, T. S. 2008. The effects of price deregulation on maize marketing margins in South Africa. Food Policy 33(3): 224-236.

[23] Trajtenberg, M. 1989. The Welfare Analysis of Product Innovations, with an Application to Computed Tomography Scanners. Journal of Political Economy, April 1989, 97(2), 444-479.

[24] Zhang, Q., Yang, H., Wang, Q., 2017. Impact of high-speed rail on China's Big Three airlines. Transportation Research Part A 98, 77-85. 